\title{
Variability along the Atlantic water pathway in the forced Norwegian Earth System Model
}

\author{
H. R. Langehaug ${ }^{1}$ - A. B. Sandø $\varnothing^{2}$ M. Årthun ${ }^{3} \cdot$ M. Ilıcak ${ }^{4,5}$
}

Received: 24 February 2017 / Accepted: 21 March 2018

(c) The Author(s) 2018

\begin{abstract}
The growing attention on mechanisms that can provide predictability on interannual-to-decadal time scales, makes it necessary to identify how well climate models represent such mechanisms. In this study we use a high $\left(0.25^{\circ}\right.$ horizontal grid $)$ and a medium $\left(1^{\circ}\right)$ resolution version of a forced global ocean-sea ice model, utilising the Norwegian Earth System Model, to assess the impact of increased ocean resolution. Our target is the simulation of temperature and salinity anomalies along the pathway of warm Atlantic water in the subpolar North Atlantic and the Nordic Seas. Although the high resolution version has larger biases in general at the ocean surface, the poleward propagation of thermohaline anomalies is better resolved in this version, i.e., the time for an anomaly to travel northward is more similar to observation based estimates. The extent of these anomalies can be rather large in both model versions, as also seen in observations, e.g., stretching from Scotland to northern Norway. The easternmost branch into the Nordic and Barents Seas, carrying warm Atlantic water, is also improved by higher resolution, both in terms of mean heat transport and variability in thermohaline properties. A more detailed assessment of the link between the North Atlantic Ocean circulation and the thermohaline anomalies at the entrance of the Nordic Seas reveals that the high resolution is more consistent with mechanisms that are previously published. This suggests better dynamics and variability in the subpolar region and the Nordic Seas in the high resolution compared to the medium resolution. This is most likely due a better representation of the mean circulation in the studied region when using higher resolution. As the poleward propagation of ocean heat anomalies is considered to be a key source of climate predictability, we recommend that similar methodology presented herein should be performed on coupled climate models that are used for climate prediction.
\end{abstract}

Keywords Thermohaline anomalies $\cdot$ Atlantic water $\cdot$ Subpolar North Atlantic $\cdot$ Nordic Seas $\cdot$ Subpolar Gyre $\cdot$ NorESM

H. R. Langehaug

helene.langehaug@nersc.no

1 Nansen Environmental and Remote Sensing Center and Bjerknes Centre for Climate Research, Thormøhlensgate 47, 5006 Bergen, Norway

2 Institute of Marine Research and Bjerknes Centre for Climate Research, PO Box 1870, 5831 Bergen, Norway

3 Geophysical Institute, University of Bergen and Bjerknes Centre for Climate Research, Allégaten 70, 5007 Bergen, Norway

4 Uni Research Climate and Bjerknes Centre for Climate Research, Allégaten 55, 5007 Bergen, Norway

5 Eurasia Institute of Earth Sciences, Istanbul Technical University, Istanbul, Turkey

\section{Introduction}

The major warm water pathway in the North Atlantic Ocean, the North Atlantic Current, and its extension into the Nordic Seas, keep the eastern North Atlantic warm compared to the western part (e.g., Brambilla and Talley 2008). Warm and cold anomalies occurring along the pathway of the North Atlantic Current are brought northwards and eventually into the Nordic Seas (Chepurin and Carton 2012; Holliday et al. 2008; Yashayaev and Seidov 2015). How such anomalous heat is formed and expressed on its way northward is still not fully understood (e.g., Krahmann et al. 2001; Årthun and Eldevik 2016). Several studies, however, suggest that the thermohaline anomalies are mainly carried northward with ocean advection (Mauritzen et al. 2006; Grist et al. 2010; Carton et al. 2011; Årthun and Eldevik 2016). Previous studies highlight the North Atlantic Subpolar Gyre strength as a key factor in controlling the warm and saline inflow 
into the Nordic Seas (Hátún et al. 2005), and others show that the extension of both the North Atlantic subpolar and subtropical gyre regulates the gateway of warm water northwards (Häkkinen et al. 2011). Recent studies suggest that heat anomalies are propagating in the Nordic Seas, along the Norwegian Atlantic Current, as warm "packets" of water (Chafik et al. 2015). These warm packets, seen as anomalous temperature at the ocean surface, occur about every 14 years and take approximately 10 years to travel from the subpolar North Atlantic and to the northern end of the Nordic Seas, the Fram Strait (Årthun et al. 2017).

Understanding the mechanisms behind the anomalous heat brought northward along the Atlantic water pathway in both nature and models would improve the confidence in decadal potential predictability and help in the selection of model for dynamical predictions (Latif and Keenlyside 2011). The interest in climate predictability has increased rapidly in the recent years, and huge efforts are put in by scientists worldwide to identify a methodology for successfully predicting the climate. Several studies have identified the subpolar North Atlantic as a particularly predictable region on interannual to decadal time scales and suggest that predictability arise from changes in the ocean circulation (e.g., Robson et al. 2012). More specifically, warmer water in the subpolar North Atlantic comes from a larger amount of heat brought northward by the ocean circulation (e.g., Matei et al. 2012; Msadek et al. 2014). Also, a more recent study demonstrates predictable skill in the Nordic Seas related to the inflow of warm water on decadal time scale (Yeager et al. 2015). However, the success of prediction on decadal time scale in the Nordic Seas appears to be limited. In a study using dynamical prediction systems based on three different climate models, only one of them showed to have some success in predicting sea surface temperature in the eastern Nordic Seas (Langehaug et al. 2017). It appears that the shallow Greenland-Scotland Ridge, separating the subpolar North Atlantic and the Nordic Seas, act as a barrier for predictability. The properties and dynamics of the warm water pathway appear to be lost or modified as it enters the Nordic Seas.

Systematic model errors are a major challenge in climate prediction (Meehl et al. 2014; Menary et al. 2015). In this study we focus on the subpolar North Atlantic and the Nordic Seas, which are challenging regions to represent in climate models (Menary et al. 2015; Langehaug et al. 2017). We here address whether or not an increased horizontal resolution in a forced global ocean-sea ice model will lead to better performance in the region of interest. We focus on variables and mechanisms that are relevant for predictability in the subpolar North Atlantic (hereafter the subpolar region) and the Nordic Seas, such as heat transport and hydrographic anomalies along the pathway of Atlantic water (Fig. 1). The Atlantic water pathway follows the poleward extension of the Gulf Stream; the North Atlantic Current and the Norwegian Atlantic Current. With the ultimate goal of successfully predicting changes related to the heat transport, our scientific questions are as follows: (1) What are the main mechanisms to improve predictability along the Atlantic water pathway? (2) How does a non-eddy resolving model $\left(1^{\circ}\right.$ horizontal grid) perform in reproducing poleward propagation of thermohaline anomalies? (3) Do we gain a significant improvement if we move to a higher resolution model $\left(0.25^{\circ}\right.$ horizontal grid $)$ ? A higher resolution will better represent the topography around the Greenland-Scotland Ridge, and therefore potentially better represent the transport of mass and heat across the ridge, allowing thermohaline anomalies to be communicated between the subpolar region and the Nordic Seas.

There are several previous studies that highlight the benefits and importance of using high resolution coupled climate models (e.g., Delworth et al. 2012; Kirtman et al. 2012). A recent study shows that coarse resolution climate models (current IPCC class models, such as the $1^{\circ}$-model used herein) have limited ability to capture decadal variability that are associated with finer scale ocean dynamics, such as ocean fronts and eddies in the Gulf Stream (Siqueira and Kirtman 2016). Hence, the study underlines that skillful climate predictions need models that can realistically represent the Gulf Stream and the associated air-sea interaction, which fundamentally change its character in eddy-resolving models (e.g., Bryan et al. 2010).

The manuscript is organized as follows. The forced global ocean-sea ice model simulations and the observational based data, as well as the methods used in our study, are presented in Sect. 2. In Sect. 3, the two model versions are assessed and compared with focus on the warm Atlantic water pathway. In Sect. 4, we discuss our results, and finally, our conclusions are given in Sect. 5.

\section{Data and methods}

\subsection{Description of observations and model setup}

To assess modeled hydrographic anomalies, we use SST from the Hadley Centre (HadISST; Rayner et al. 2003), and upper-ocean salinity from the Ishii Ocean Analyses Project (Ishii et al. 2006). The latter consists mainly of data from the World Ocean Database, but also includes data from ARGO floats. Both datasets are available on a $1^{\circ}$ longitude $\times 1^{\circ}$ latitude grid with monthly temporal resolution.

This study is both an assessment against available observations, and a comparison of two versions of the Norwegian Earth System Model (NorESM; Guo et al. 2016). In the following the high resolution $\left(0.25^{\circ}\right.$ horizontal resolution $)$ version will be called NorESM1-H, and the medium resolution 


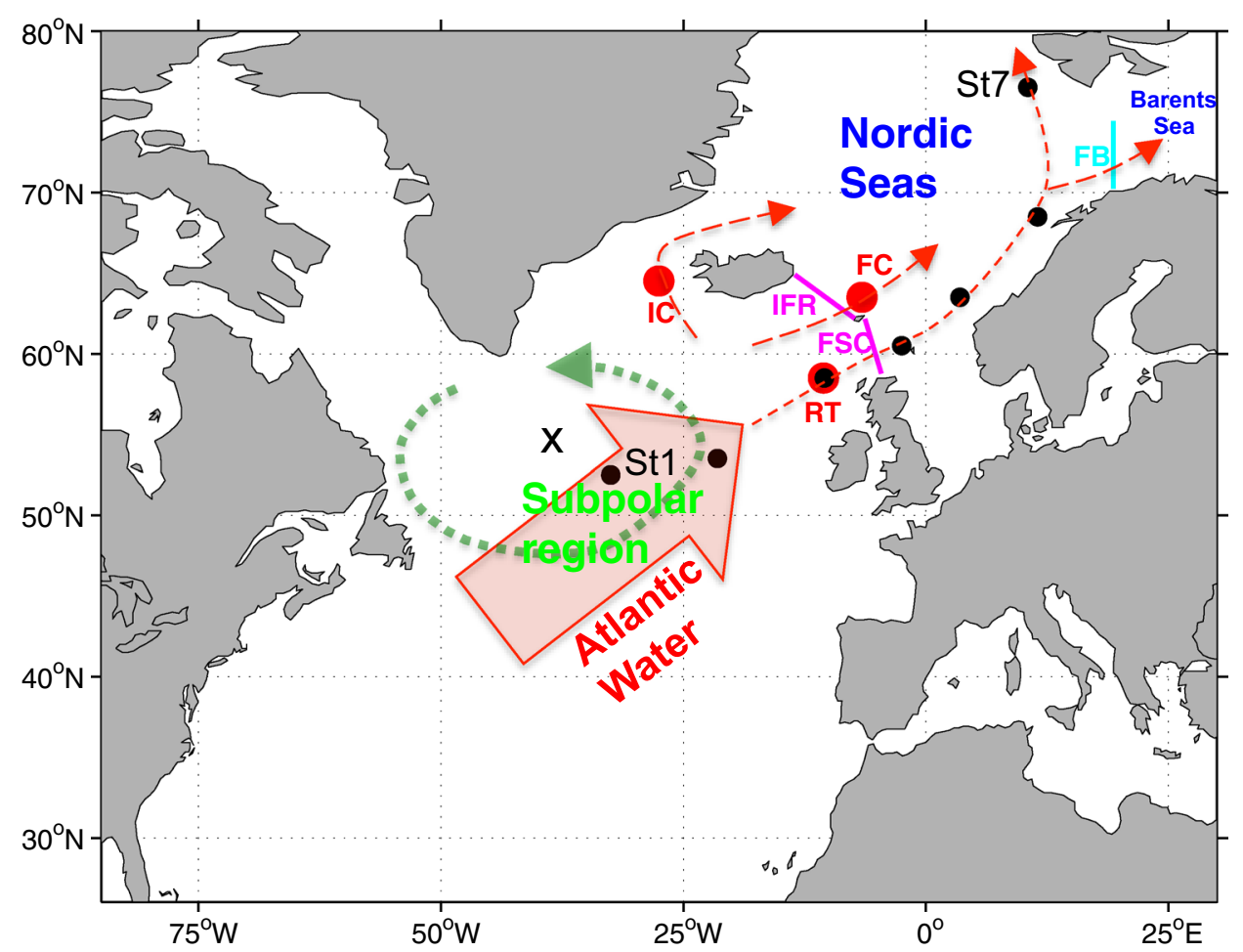

Fig. 1 The map shows the key regions for this study; the warm Atlantic water pathway via the Subpolar Gyre (green dashed curve), across the Greenland-Scotland Ridge, and along the eastern rim of the Nordic Seas. Seven stations (black circles) are located along the pathway (St1, St2, ... St7), and are used to track northward propagation of hydrographic anomalies in the Atlantic Water. The inflow of Atlantic Water to the Nordic Seas can be separated into three currents:

$\left(1^{\circ}\right)$ NorESM1-M. Both versions are forced with realistic interannual COREv2 atmospheric forcing (Large and Yeager 2009) for a 60-year period (1948-2007). Surface fluxes are calculated using the bulk formulae as described in Large and Yeager $(2004,2009)$. The medium resolution version has been used and assessed in several previous studies (Danabasoglu et al. 2014, 2016; He et al. 2016; Ilicak et al. 2016), whereas the high resolution has only been investigated in one previous study (Guo et al. 2016).

The ocean component (MICOM; Miami Isopycnic Coordinate Ocean Model) in NorESM uses $\sigma_{2}$-isopycnals (potential density referenced to $2000 \mathrm{dbar}$ ) as the vertical coordinate and Arakawa C-grid in the horizontal. There are 51 $\sigma_{2}$-layers in the vertical, ranging from 28.202 to $37.800 \mathrm{~kg}$ $\mathrm{m}^{-3}$ (Bentsen et al. 2013). In addition, there are two model layers in the sea surface mixed layer where potential density can evolve freely. The mixed layer depth in the model is parameterized by a turbulent kinetic energy balance equation based on Oberhuber (1993) that has been extended with parameterized mixed layer re-stratification according to Fox-Kemper et al. (2008). The parameterized diapycnal mixing consists of several components: Parameterized the Irminger Current (IC), the Faroe Current (FC), and the Rockall Trough (RT). The main northward heat transport occurs east of Iceland, and is captured by two sections between Iceland and Scotland: Iceland-Faroe Ridge (IFR) and Faroe-Shetland Channel (FSC). A section between Fugløya and Bjørnøya (FB) captures the heat transport into the Barents Sea. The approximate center of the Subpolar Gyre is marked by the cross

shear-induced mixing depends on the local gradient Richardson number following Large et al. (1994) with a maximum allowable diffusivity of $0.005 \mathrm{~m}^{2} \mathrm{~s}^{-1}$ except in a depth interval extending from the bottom to $300 \mathrm{~m}$ above the bottom where, in order to provide sufficient mixing downstream of overflows, the maximum allowable mixing is gradually increased to $0.25 \mathrm{~m}^{2} \mathrm{~s}^{-1}$ at the bottom; A fraction of the energy extracted from the mean flow by bottom drag drives mixing in the lowermost isopycnic layers (Legg et al. 2006); Tidal-induced mixing is parameterized according to Simmons et al. (2004); The background mixing is latitudedependent and vertically constant (Gregg et al. 2003), giving a gradual decrease of diffusivity towards the equator with a value of $10^{-5} \mathrm{~m}^{2} \mathrm{~s}^{-1}$ at $30^{\circ}$ latitude.

In the NorESM1-H simulation, isopycnic tracer diffusivity and thickness diffusivity appropriate to Gent and MacWilliams (1990) GM parameterization is set to zero. The reason for this set up was initially to explore the effect of resolved mesoscale eddy field in the tropics and subtropics. However, with quarter degree horizontal resolution, NorESM1-H does not resolve all mesoscale eddies. In practice, beyond about $40^{\circ}$ north eddy activity is not resolved 
(Hallberg 2013). Although NorESM1-H does not resolve eddy activity in our regions of interest in this study, we believe that the model experiment can give valuable information on climate variability on multi-annual time scales (we herein use a 3-year low-pass filter, further described below, to investigate variability on interannual to decadal time scales). It has furthermore been shown that the contribution from the eddy transport to the mean poleward heat transport north of $50^{\circ} \mathrm{N}$ in the Atlantic sector is negligible compared to that from the mean transport (e.g., Volkov et al. 2008; Kirtman et al. 2012). The main motivation for using a higher resolution model for this study lies in its better representation of bathymetry and ocean currents close to the Greenland-Scotland Ridge (Guo et al. 2016).

In NorESM1-H, the viscosity values are lower than in NorESM1-M, which leads to higher velocity values in NorESM1-H. In the North Atlantic, this is especially seen in the Gulf Stream separation area (shown in Figs. 7, 14).

NorESM1-H was only run for two repeated cycles (i.e., 120 years) due to the costly integration of the model. NorESM1-M was run for five repeated cycles (i.e., 300 years). We use the last cycle for each model version, i.e., the fifth cycle (model years 241-300) for NorESM1-M and the second cycle (model years 61-120) for NorESM1-H. However, when we compare sea surface temperature (SST) and sea surface salinity (SSS) biases from the two model versions, we use the same time averaged periods for both model versions (model years 100-120). SSS restoring was applied globally to avoid local salinity drift. The restoring was applied as a salt flux with a piston velocity of $50 \mathrm{~m} / 300$ days.

We have tested whether or not there is a model drift in NorESM1-H that has only been run for two cycles, and Fig. 2 shows that at least for SST, there seems to be no particular model drift for NorESM1-H. The overall pattern of the trends in the SST over the time period 1948-2007 for the HadISST data and the two model versions is generally comparable with positive trends along the Gulf Stream/North Atlantic Current and in the northern Nordic Seas, and negative trends close to Iceland. The trends are perhaps slightly too large in NorESM1-H compared to HadISST, whereas NorESM1-M shows in general an underestimation of the trends. For NorESM1-H to have an additional model drift, we would expect to see a comparable change in the mean SST for all grid cells, which is not the case. On the other hand, deeper parts of the ocean need longer time to adjust, and we might find a model drift there.
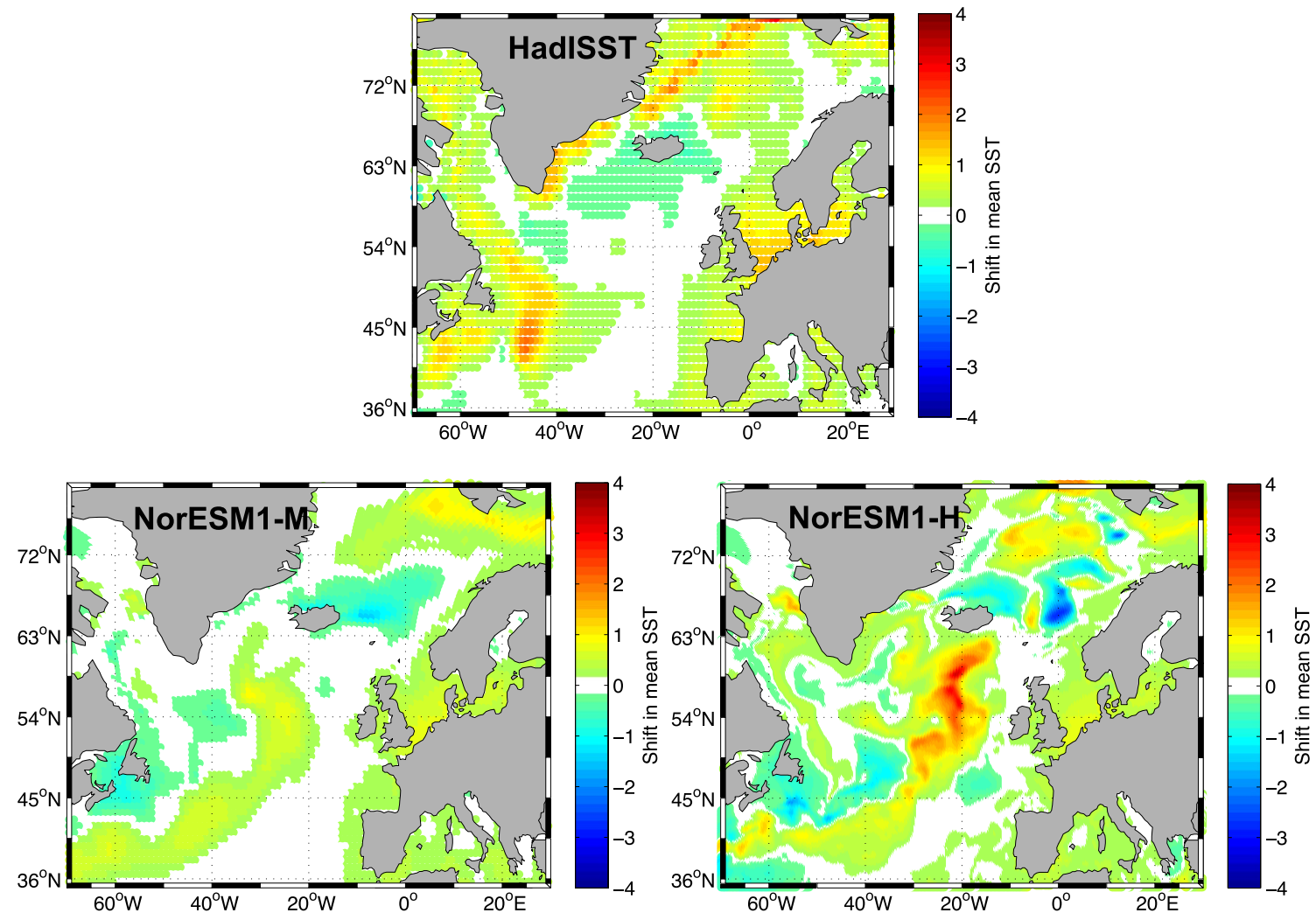

Fig. 2 Map showing the change in the mean SST over the time period 1948-2007. The change in the mean is defined as the difference between the end point and start point of the linear trend in SST for each grid cell. Positive values means a warming of the ocean surface 
We have also compared the trend in the volume and heat transports into the Nordic and Barents Seas between the two model versions for the time period 1948-2007, and we find that NorESM1-H and NorESM1-M have always the same sign of the trend. In two out of three sections (Iceland-Faroe Ridge and Fugløya-Bjørnøya, see Fig. 1), the steepness of the linear trend (both for volume and heat transport) is larger for NorESM1-M than in NorESM1-H (not shown). Hence, according to these trends, a model drift in NorESM1-H (due to short spin-up time) appears not to be the case. Note that if such model drift would be the case, it would only affect the results where we compare the long-term mean between the model versions and observations. When investigating variability, all time series are filtered as described in the next section, and hence, long-term trends are removed.

\subsection{Statistical methods}

The characteristics of hydrographic anomalies are objectively assessed using a complex principal component (CPC) analysis (Horel 1984), which allows for a decomposition of the original time series into the fewest possible number of modes (complex empirical orthogonal functions). The importance of each mode is defined as the proportion of variance explained by each principal component. The elements of the CPC time series can furthermore be written in the form of amplitudes and phase angle.

Time series from seven stations (i.e., grid cells) along the Atlantic water pathway have been filtered before applying the cross-correlation and the CPC analysis. A 3-30-year Butterworth band-pass filter has been chosen. The 3-year low-pass filter is used to smooth the data, and the 30-year high-pass filter is used to remove long-term variability, e.g., such as the Atlantic Multidecadal Variability (AMV; Knight et al. 2005). If the high-pass filter is not applied for HadISST, the CPC analysis does not show a time difference from the southernmost to the northernmost station for individual anomalies, but rather a standing pattern of anomalies that is comparable to the temporal evolution of the AMV index in the time period 1950-2010 (warm phase-cold phasewarm phase; Knight et al. 2005). A power spectrum analysis shows that we are keeping the periods with most energy by using the chosen Butterworth band-pass filter (3-30-year band-pass filter; Fig. 3). Regarding both SST and subsurface salinity (at $200 \mathrm{~m}$ ) in the Nordic Seas, NorESM1-M and NorESM1-H have significant peaks with a 20 years period. Observations show peaks at 16 years, but the peak is only significant for SST.

Before performing correlations using HadISST, we have removed five data points at both ends of the time series.
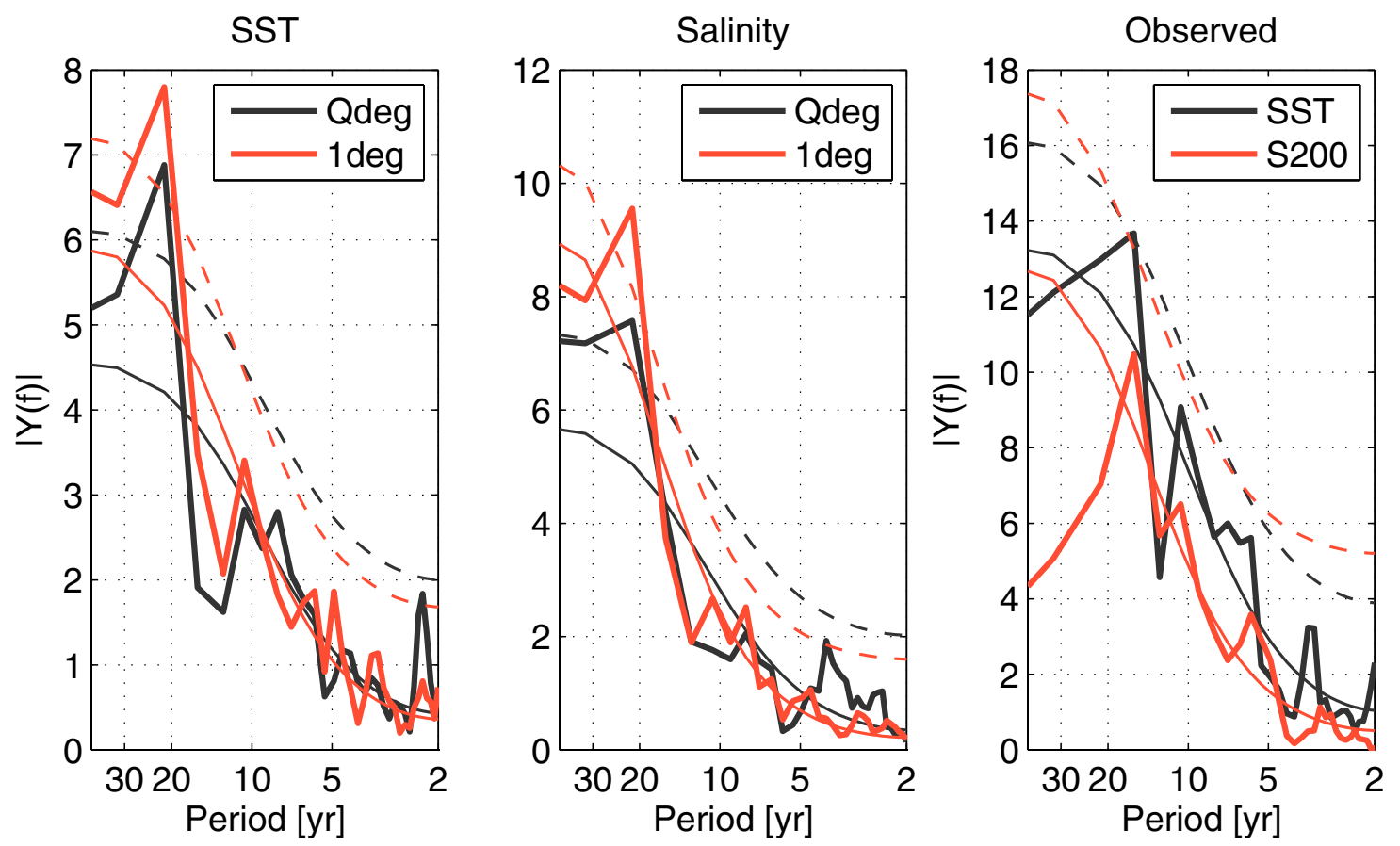

Fig. 3 Power spectrum based on the unfiltered annual mean SST and subsurface salinity (at $200 \mathrm{~m}$ depth) time series from Station 5 (Fig. 1, black circles) for the period 1948-2007. The power spectrum based on observations is using HadISST for SST and Ishii for subsurface salinity. In addition, the theoretical red noise spectrum (thin solid lines) is shown, computed by fitting a first-order autoregressive

process, with a 95\% confidence interval (thin dashed lines) around the red noise The power spectra are computed using the multitaper method (Ghil et al. 2002), with the number of tapers $K=3$. The reason for comparing the spectra at Station 5 is that the Atlantic water pathway is well confined at this station 
This is to avoid 'bad' data after the filtering process. The results from HadISST are sensitive to the removal of data points, whereas the Ishii data and model data are not sensitive. However, five data points have also been removed from the Ishii data and the simulated time series for consistency. The statistical significance level at $90 \%$ is achieved by the standard two-sided Student's t-test (e.g., O'Mahony 1986). For significance testing, the method of Chelton (1983) is used to estimate the effective number of degrees of freedom.

\section{Results}

In this study, we focus on the surface signature of the warm Atlantic water pathway when we investigate sensitivity to changes in horizontal model resolution. Our hypothesis is that the high resolution performs better than the medium resolution with respect to thermohaline properties and variability along the Atlantic water pathway.

\subsection{Ocean surface climate}

In the introduction we pointed out the difficulties in representing the subpolar North Atlantic in climate models. The difficulties in representing this region are evident in Figs. 4 and 5, where the subpolar region and the Nordic Seas sticks out with large biases both for SST and SSS. Overall, NorESM1-M performs better than NorESM1-H. Particularly, the simulated mean hydrography along the

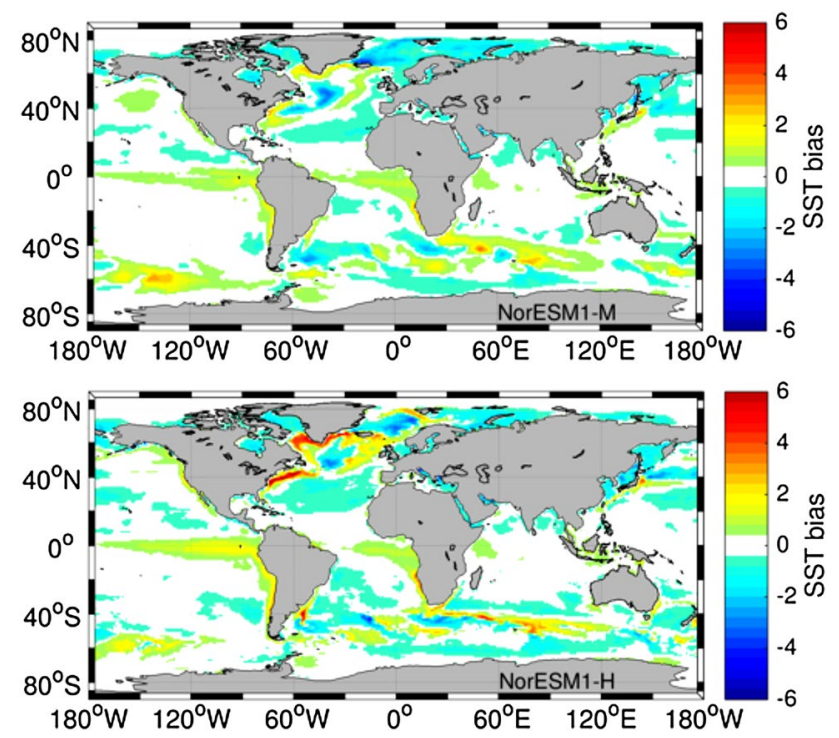

Fig. 4 SST biases; the difference between HadISST data and the mean SST from the two model simulations (averaged over the model years 100-120, corresponding to the period 1987-2007). Positive values mean that model simulations are warmer than observations
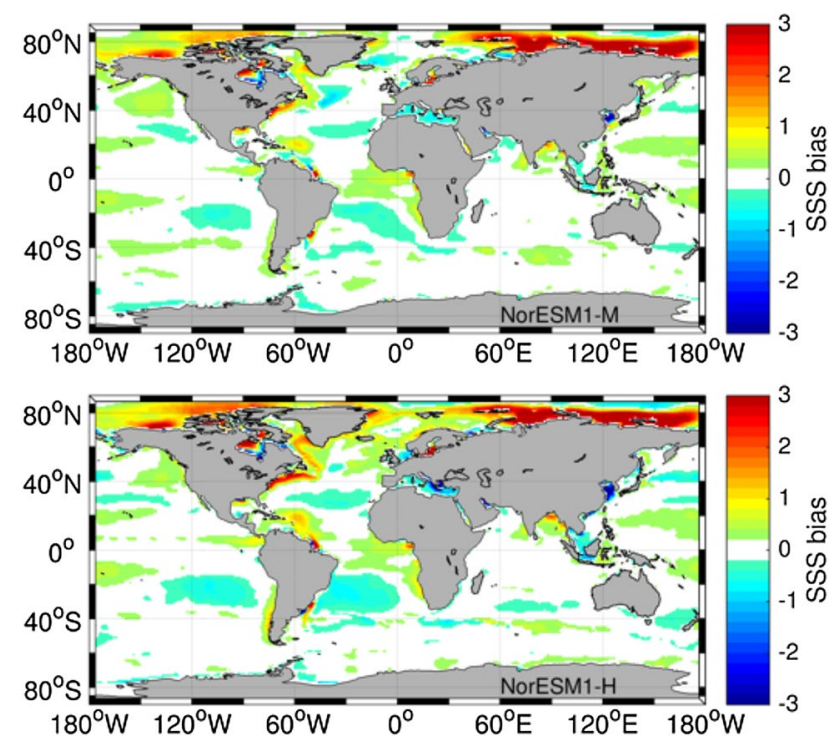

Fig. 5 SSS biases; the difference between Ishii data and the mean SSS from the two model simulations (averaged over the model years 100-120, corresponding to the period 1987-2007). Positive values mean that model simulations are more saline than observations

rim of the subpolar region and the Nordic Seas is poorer in NorESM1-H.

By comparing the spread of Atlantic water, here represented by the position of the isoline for $6{ }^{\circ} \mathrm{C}$ (Fig. 6), we again find that NorESM1-M is, overall, more similar to HadISST than NorESM1-H. In NorESM1-H, the Atlantic water extends further north in the Nordic Seas and further west in the subpolar region than both HadISST and NorESM1-M. This is most likely related to differences in

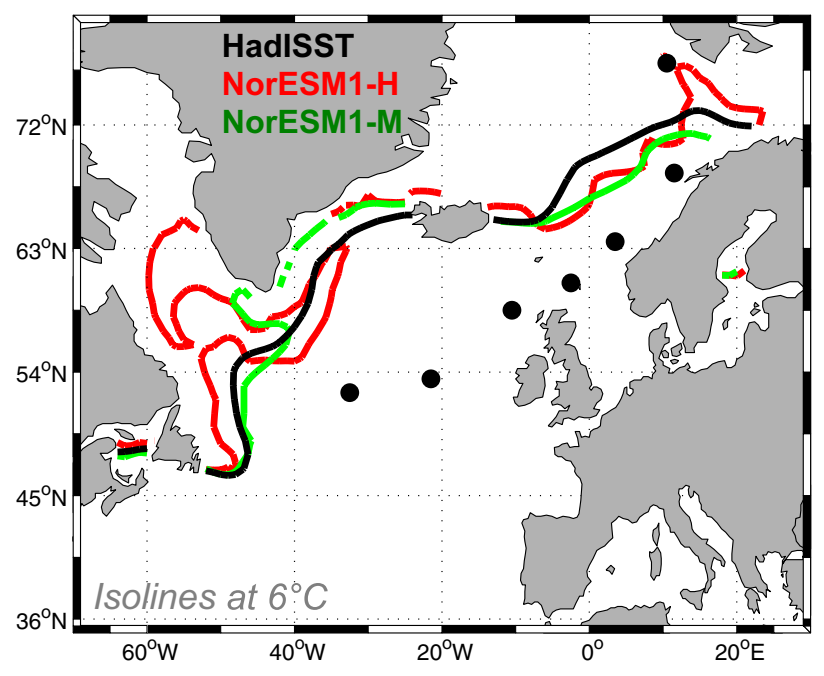

Fig. 6 Isolines of $6{ }^{\circ} \mathrm{C}$ indicate how far north and west the Atlantic water reaches. Isolines are drawn from the SST average over the period 1948-2007 
the surface ocean circulation between the two model versions. In NorESM1-H boundary currents are in general stronger, there is a northeastward direction of the North Atlantic Current, and there are two branches of Atlantic water in the southern part of the Nordic Seas (Fig. 7), in agreement with observations (Orvik and Niiler 2002). In particular, in NorESM1-H, the branches of the North Atlantic Current in the northeastern Atlantic with a strong boundary current in the Iceland basin is more consistent
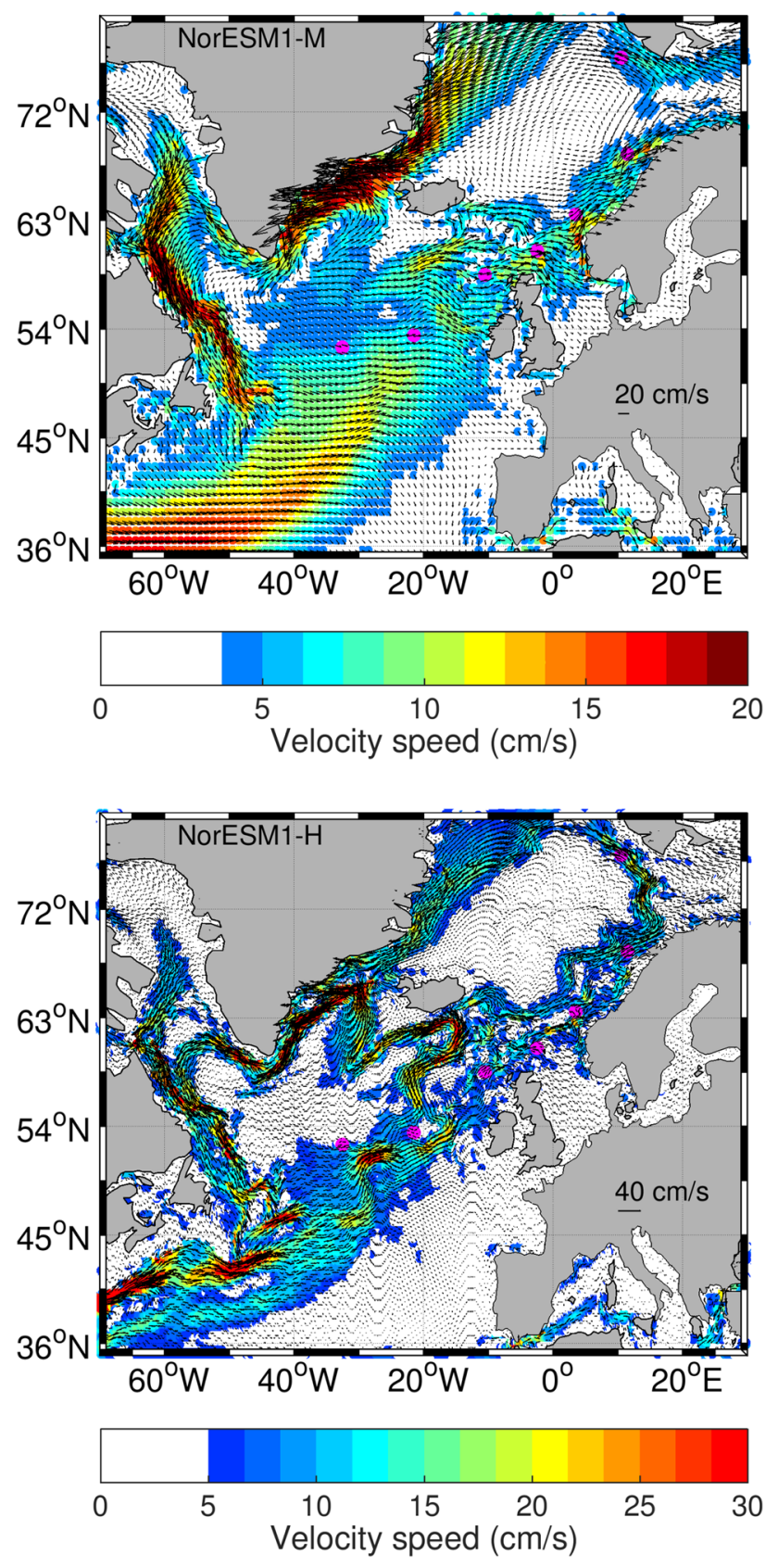

Fig. 7 Mean currents in the mixed layer averaged over the period 1948-2007. Color shading shows the velocity speed of the currents. For NorESM1-H, only every 5 th velocity vector is shown with observations than the circulation in NorESM1-M (e.g., Pollard et al. 2004; Brambilla and Talley 2008). This boundary current and connection with the Irminger Current in the Irminger basin is not found in NorESM1-M. Furthermore, in NorESM1-M, the North Atlantic Current has a more zonal direction and there is no clear separation of the branches in the Nordic Seas (Fig. 7). The West Spitsbergen Current which is a boundary current flowing over shelf topography in northeastern Nordic Seas is also captured much better in NorESM1-H. Overall, all currents in NorESM1-H over topography are sharper and less diffuse compared to NorESM1-M.

The above findings appear contradictory; NorESM1-H having the most realistic circulation of the North Atlantic Current and its branches in northeastern North Atlantic, but also having the largest SST and SSS biases, particularly in the western subpolar region. Similar results are also found in other studies comparing different model resolutions; warmer and more saline water along the rim of the subpolar region in the higher resolution version (e.g., Kirtman et al. 2012; Marzocchi et al. 2015). The reason for this evident surface bias has previously been investigated in high resolution models (Treguier et al. 2005; Rattan et al. 2010), and the studies found that this is a model drift caused by too large input of warm and saline Atlantic water to the Labrador Sea with the rim currents in the Iceland and Irminger basin. This is consistent with Fig. 2, where NorESM1-H has a SST increase over the period 1948-2007 along the rim current in western subpolar region that is not seen in NorESM1-M (partly seen in HadISST, but then the change extends towards the Arctic). Furthermore, and equally important for the model drift, is the freshwater pathways around Greenland (Rattan et al. 2010). In this study, we also find that the surface East Greenland Current is too saline in NorESM1$\mathrm{H}$ (Fig. 5). We believe that this is probably due to lack of GM coefficients at high latitudes in the NorESM1-H simulation (see Sect. 2.1). Resolving eddies should flatten the isopycnals in the Irminger Current and Labrador Sea. In NorESM1-M, this is achieved by isopycnal diffusion, however NorESM1-H suffers not fully resolving mesoscale eddies in those regions.

The SST and SSS biases seen in the central and eastern subpolar region in both model versions (Figs. 4, 5) are related to shift in the position of the North Atlantic Current. This is a well-known problem in IPCC class of models (e.g., Kirtman et al. 2012; Langehaug et al. 2012). In NorESM1-H, the surface circulation related to the North Atlantic Current is improved as described above, and hence, the cold bias is reduced. However, there are still challenges, with the North Atlantic Current still being too far east and the large input of Atlantic water towards the Labrador Sea. 


\subsection{Anomalies of temperature and salinity along the Atlantic water pathway}

We have selected seven stations along the Atlantic water pathway from the subpolar region to the northern Nordic Seas (Fig. 1, black circles; consistent with the observational study by Årthun et al. 2017). Investigating annual mean salinities from Ishii clearly show a relationship between salinity at the northernmost station and with all other stations, but with a larger time lag as the distance increases from the northernmost station (Fig. 8). In particular, annual mean subsurface salinities at the core of Atlantic water (at $200 \mathrm{~m}$ depth; Chepurin and Carton 2012) show a time lag of 6 years between $\mathrm{St} 1$ and St7, implying a slow northward propagation of saline or fresh anomalies. However, a similar analysis on annual mean sea surface salinity (SSS) from the two model versions reveals no such hints of a similar pattern (not shown). This might be due to the SSS relaxation in the models. Changing the relaxation piston velocity for sea surface salinity field needs further investigation, however this is beyond the scope of this paper. We therefore also investigate subsurface salinity in the models, which is much less sensitive to the SSS relaxation, and ocean surface processes such as evaporation and precipitation. However, a similar correlation pattern is not found in the two model versions neither for subsurface salinity (not shown).

We have not done a similar analysis for subsurface temperature, as there are no SST relaxation/correction-SST freely evolves in the model simulations. On the other hand, we have tested the results with winter SST, which represents a deep mixed layer during winter, e.g., winter SST has been shown in previous studies to reflect the heat content in the mixed layer (Chepurin and Carton 2012).

HadISST also indicate a time lag of about 6 years (Fig. 9), but the correlations are not significant for the two

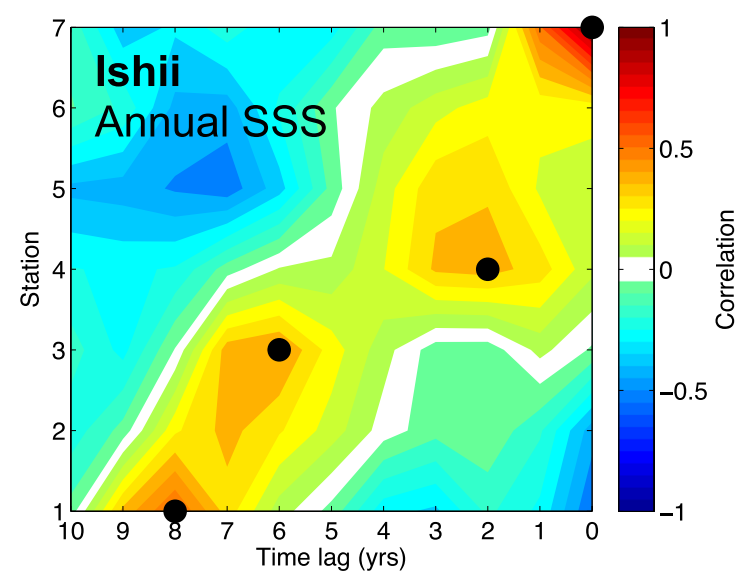

Fig. 8 Cross-correlation of annual mean SSS (left) and subsurface salinity at $200 \mathrm{~m}$ depth (right) from Ishii between the northernmost station and all seven stations (Fig. 1, black circles). Black circles southernmost stations. Comparing the HadISST correlation pattern with the correlation pattern from the two models is somewhat challenging, as both model versions seem to have similarities with HadISST. Both versions show a positive correlation pattern from St1 to St7. However, the time lag of the maximum correlation for each station differs and also the magnitude of the correlation. Here we consider the timing to be an important factor, i.e., when the SST anomaly is reaching the different stations is essential to know in terms of climate predictability. Considering the time lag, NorESM1-M appears to be most similar to HadISST in the Nordic Seas, whereas NorESM1-H appears to be most similar to HadISST in the subpolar region. The time lags in NorESM1-H are also most similar to the time lags identified for observed sub-surface salinity (Fig. 9).

The magnitude of the correlations is weak and non-significant south of the Greenland-Scotland Ridge for winter SST (Fig. 9). Somewhat unexpected, the annual SST in the model simulations gives higher correlations overall compared to using winter SST (compare Figs. 9, 10). The cross-correlations for HadISST remain more or less the same. Now the differences in the time lags between the two model versions are more evident; NorESM1-M is most similar to HadISST in the Nordic Seas, whereas NorESM1-H is most similar to HadISST in the subpolar region, and also to the overall time lags related to observed sub-surface salinity. We have tested whether the correlations in NorESM1-M and NorESM1-H are significantly different, and we find that most of the peak correlations (black dots in Fig. 10) are significantly different at a significance level of 0.1 (red dots in Fig. 10). This is done by testing the null hypothesis that the correlations in the two model versions are the same, using the Fisher transformation (Fisher 1921).

Another way of investigating to what extent hydrographic anomalies are propagating along the Atlantic

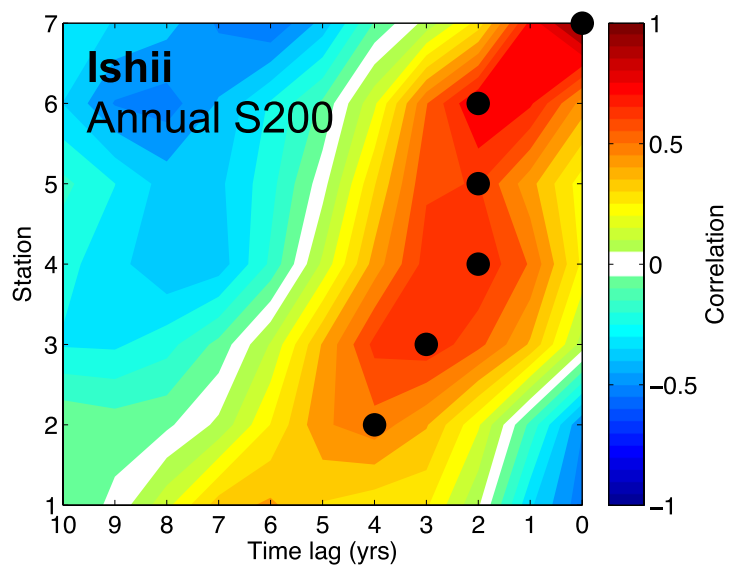

mark the maximum significant positive correlation for each station. Time series are filtered by a 3-30-year Butterworth band-pass filter 

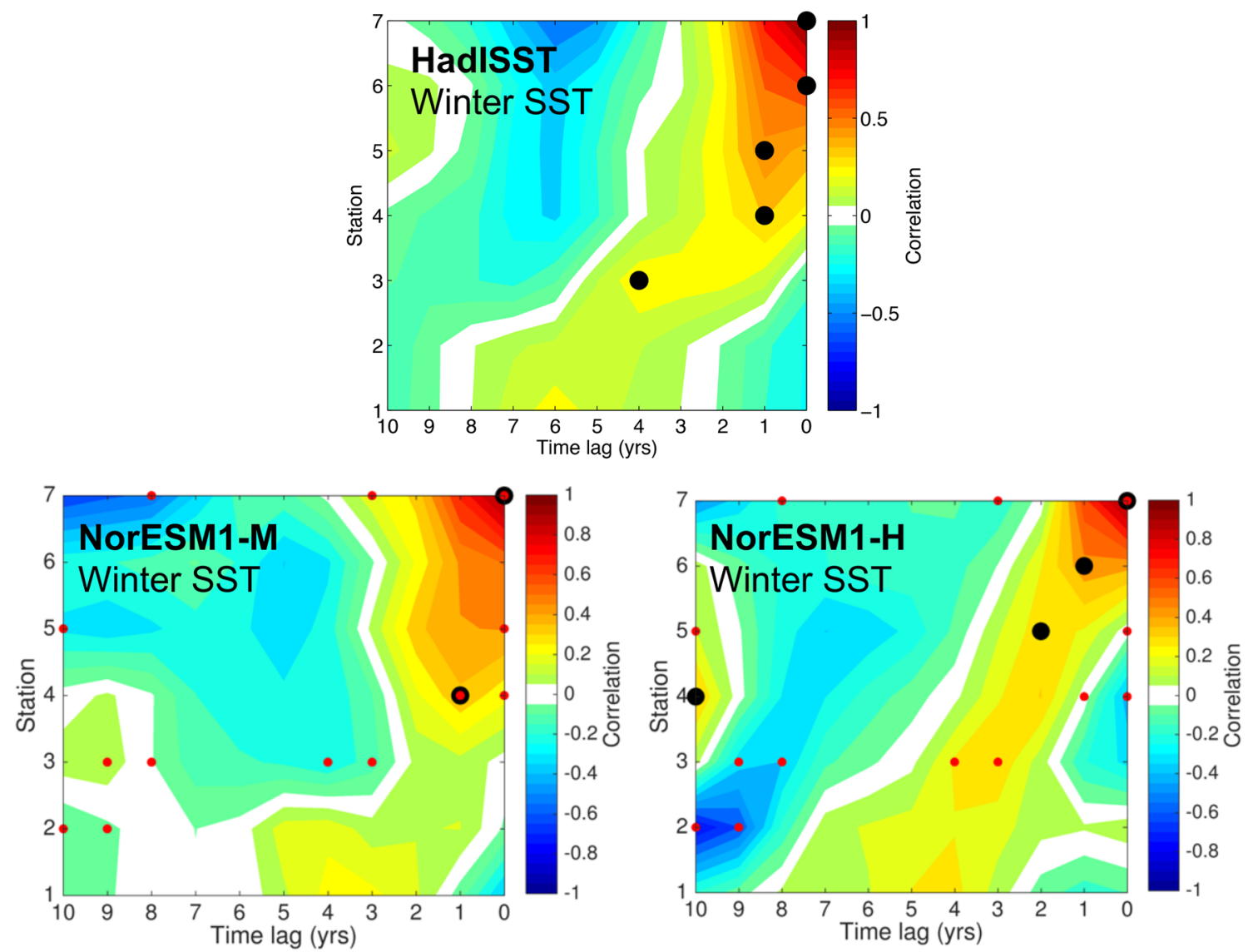

Fig. 9 Same as Fig. 8, but for Winter (Jan-Apr) SST. The red dots show where the correlation is significantly different between NorESM1-H and NorESM1-M

water pathway is by applying a complex principal component (CPC) analysis, as described in Sect. 2. The first mode, explaining $65 \%$ of the total variability, from the CPC analysis based on annual mean SST from HadISST shows that warm or cold anomalies are evident continuously from the southernmost to the northernmost station (Fig. 11). The time difference between the southernmost and the northernmost stations differs for the individual anomalies but appears to be in the range between 5 to 10 years, in accordance with the 6 years time lag found in the cross-correlation (Fig. 10). This would be the time it takes the anomalies to be advected poleward if we assume they are transported by the ocean circulation. Furthermore, the anomalies appear to occur with a relatively constant frequency, with about 5 to 10 years between each new anomaly, but the length of the anomalies vary and also the poleward development of the anomalies (strengthening and weakening) vary. How an anomaly can be strengthened or reduced along the Atlantic water pathway in the Nordic Seas as a response to anomalous forcing has previously been described by e.g., Furevik (2001). We also note that the anomalies most of the time shift from warm-to-cold or vice versa, and rarely two warm or cold anomalies follow each other.

Both model versions perform well, showing similar results as HadISST (Fig. 11). We find a relatively large time difference between $\mathrm{St} 2$ and St3, and this appears as a weak anomaly between St 2 and St3. This is consistent with the cross-correlation analysis, which shows weak correlation around St2 and St3 (Fig. 10). This is particular the case for NorESM1-M. Note that the cross-correlation includes the total variability of the temperature, whereas the results from the CPC analysis only explain part of the temperature variability. As mentioned, the temperature pattern from HadISST's first mode explains $65 \%$ of the total temperature variability in HadISST. For the two models, the result is 58 and $51 \%$ for NorESM1-M and NorESM1-H, respectively. This means that the temperature pattern we find in the observations and models from the first mode can explain a large part of the temperature variability, but at the same time there is additional variability that can have a completely different pattern than what is illustrated in Fig. 11.

A similar pattern for annual mean SSS as for annual mean SST, i.e., a warm anomaly coinciding with a positive saline 

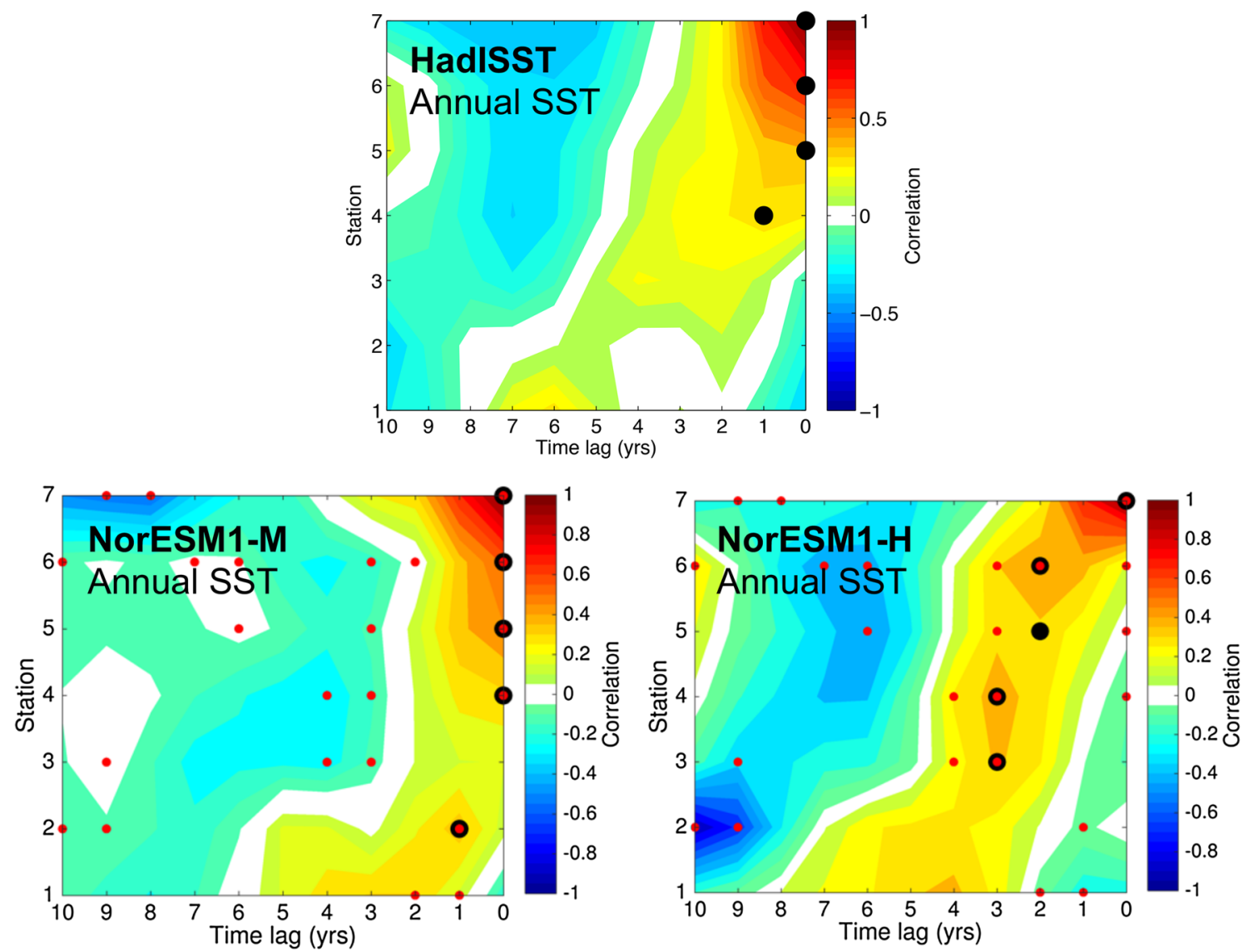

Fig. 10 Same as Fig. 8, but for annual mean SST. The red dots show where the correlation is significantly different between NorESM1-H and NorESM1-M

Fig. 11 First mode of the CPC analysis based on band-pass filtered SST time series from the seven stations (Fig. 1, black circles).
HadISST

Annual SST

NorESM1-M Annual SST
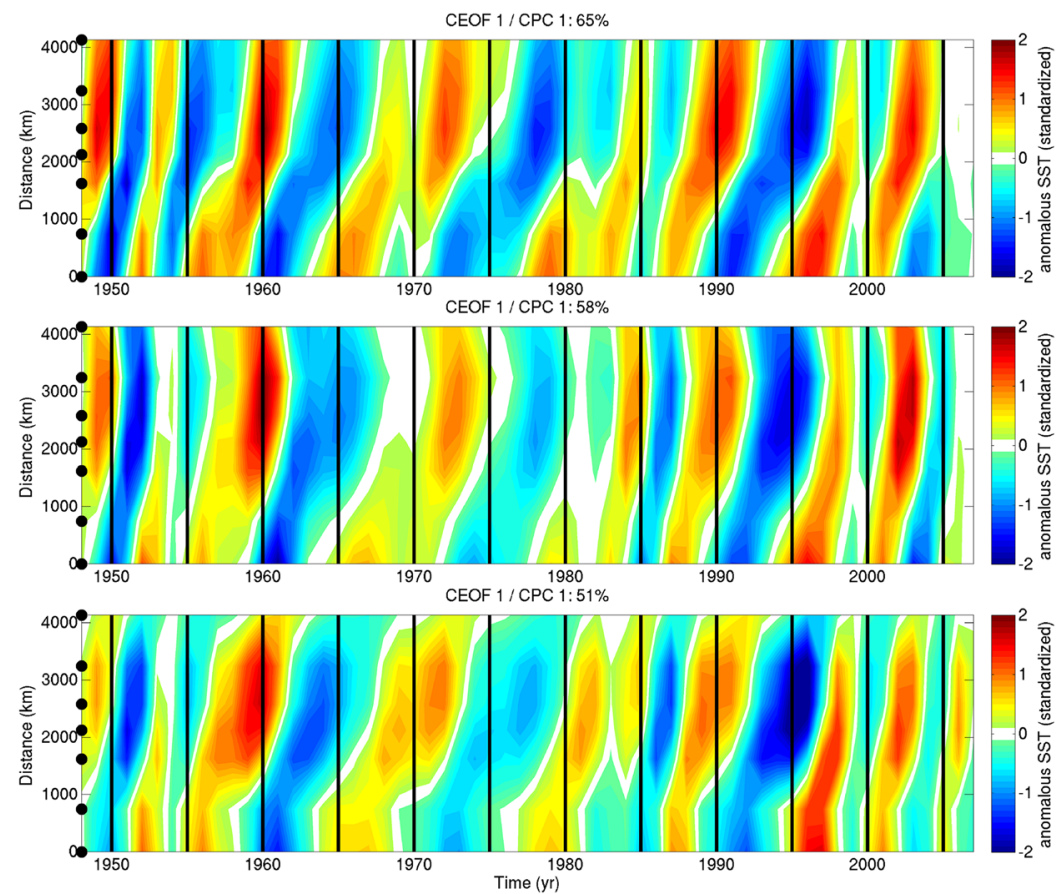

NorESM1-H Annual SST 
anomaly and vice versa, would strengthen the case that the anomalies along the Atlantic water pathway are mainly caused of advective origin. Correlating the time series of observed annual mean SST and annual mean subsurface salinity at each station, we find that correlations are in the range $0.34-0.68$ and are statistically significant except at St 6 and 7. Although correlations are low, they in general support the hypothesis that anomalies are of advective origin. The two model versions mainly show the same as observations, except at St 5, with correlations in the range 0.30-0.85 (disregarding St 5). Five out of seven stations show significant correlations between temperature and salinity for NorESM1$\mathrm{H}$, whereas four stations show significant correlations for NorESM1-M.

We have also investigated subsurface salinity with the CPC analysis. From the CPC analysis on SST it was clear that the both model versions have warm and cold events at the correct time (Fig. 11). On the other hand, the simulated saline and fresh anomalies do not appear to occur at the correct time, except for some cases, such as the large fresh anomaly starting around 1970 in the subpolar region (Fig. 12). This is most probably the signal from the Great Salinity Anomaly (Belkin et al. 1998). Again, we find in NorESM1-M a relatively large time difference between anomalies at St2 and St3. This appears as a discontinuity in the poleward path (Fig. 12).

In summary, the cross-correlation analysis reveals that the overall time lag between the southernmost and northernmost station is most realistic in NorESM1-H. We find that the correlations in NorESM1-H is significantly higher at longer time lags than in NorESM1-M. The time lags in NorESM1-H is more consistent with the time lags of observed sub-surface salinity, and also with HadISST in the subpolar region. Furthermore, the CPC analysis shows a discontinuity in the path for NorESM1-M between St2 and St3, which is not found to such an extent in observational data. Altogether, NorESM1-H appears to be most appropriate in representing hydrographic variability along the Atlantic water pathway.

In order to estimate the spatial extent of the SST anomalies found along the warm Atlantic water pathway, we have correlated the time series from the CPC analysis and the band-pass filtered SST time series in all grid points. This analysis is done for selected stations and gives an indication on how far away from the stations we can find co-variability (Fig. 13). The SST anomalies related to the first station are mainly centered in the subpolar region for both HadISST and the two model versions, with NorESM1-M having the least extent. The anomalies related to the third station spread out between Iceland and Bay of Biscay in HadISST and NorESM1-M. In NorESM1-H, the anomaly also spreads towards the southern tip of Greenland. Further north, within the Nordic Seas, the longitudinal extent of co-variability for the fifth station largely overlaps in HadISST and the two model versions, stretching from the English Channel and towards the Fram Strait. In HadISST, a small shift northward of the spatial domain of the SST anomaly is found when moving from one station to another in the Nordic Seas (not shown). This is also seen at the southern part of the domain in NorESM1-M, but it is not as clear in the north. In NorESM1-H, a northward shift of the domain is clearly seen from St5 to St7 (not shown). This is consistent with what we found in Fig. 10; in HadISST and NorESM1-M the anomalies occur at the same time for the three northernmost
Fig. 12 First mode of the CPC analysis based on band-pass filtered time series of subsurface salinity from the seven stations (Fig. 1, black circles)
Ishii Annual S200

NorESM1-M Annual s200

NorESM1-H Annual s200
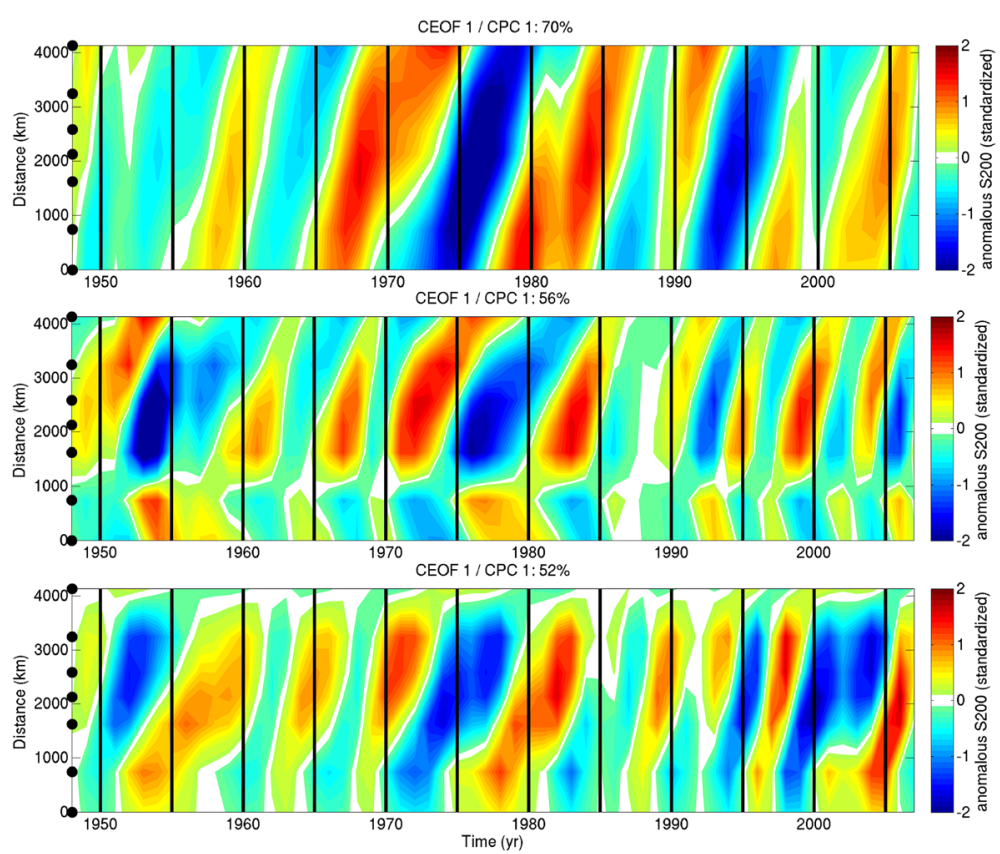

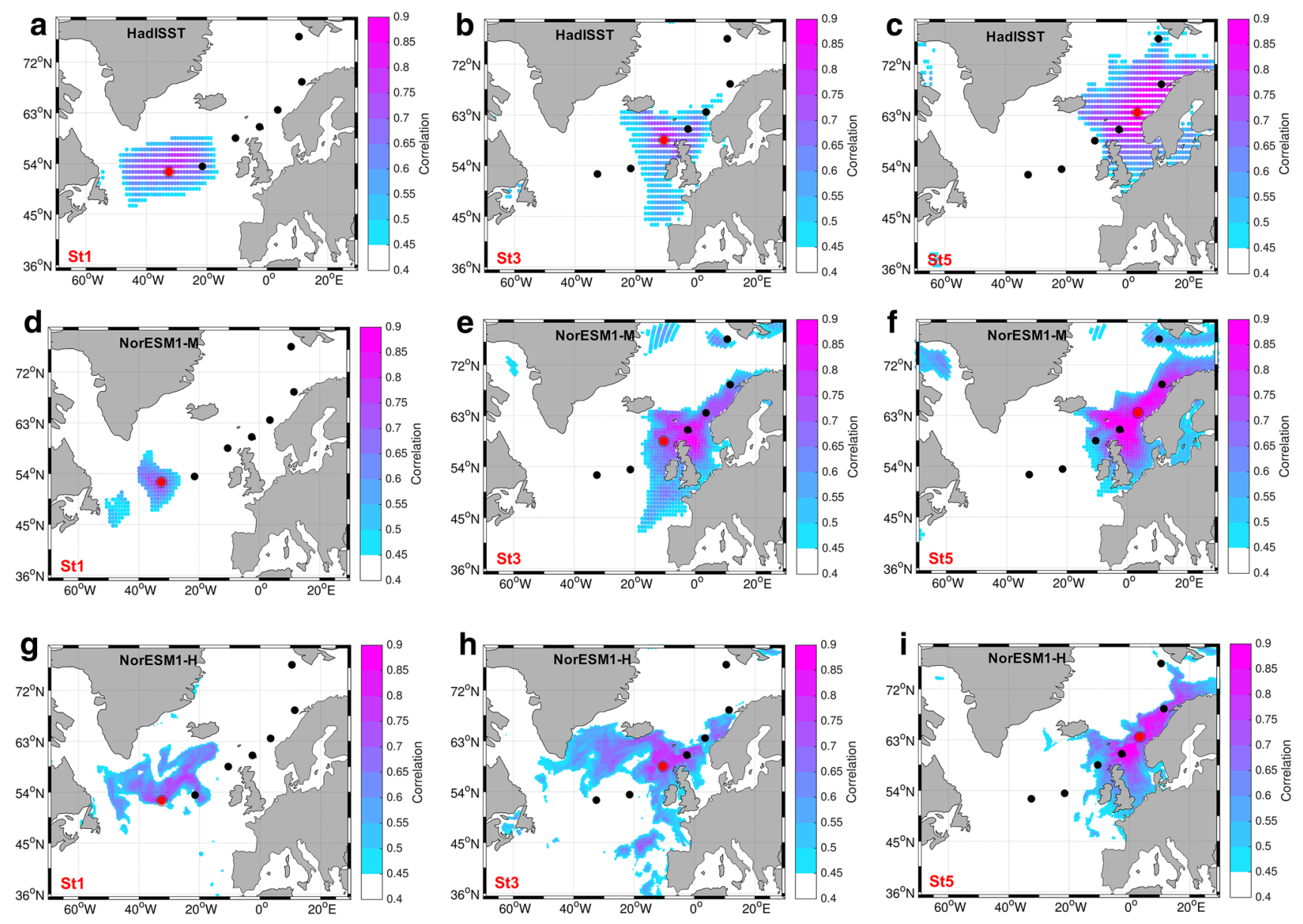

Fig. 13 Correlation between selected time series at specific stations in the CPC analysis (Fig. 11) and band-pass filtered SST in each grid point. The coloured areas show significant correlations within the interval 0.45-0.9

stations, whereas there is a time lag between these stations for NorESM1-H.

The rather large spatial extent of the co-variability of the SST anomalies is also shown in Arthun et al. (2017), using the same observational data but different approach. Marzocchi et al. (2015) investigated the warm anomaly in the subpolar region in 1998 (consistent with our Fig. 11), also covering large parts of the central subpolar region. The 1998-anomaly spread from the southwestern part of subpolar region and towards the eastern subpolar region.

\subsection{Improved Atlantic water inflow into the Nordic Seas in high resolution}

Simulated northward volume and heat transports have been assessed in the Faroe-Scotland section (FSC), over the Iceland-Faroe Ridge (IFR) and in the Fugløya-Bjørnøya section (FB). These sections capture the main sources of heat transported into the Nordic Seas and the Barents Seas (Fig. 1). We here focus on volume and heat transport related to Atlantic water, and therefore only the isopycnal layers with northward flowing water are taken into account when calculating the volume and heat transport.

Heat transports in the Nordic and Barents Seas are highly dependent on volume transport on monthly-to-interannual times scales (Orvik and Skagseth 2005; Årthun et al. 2012). Compared to the observed mean volume and heat transports of $2.7 \mathrm{~Sv}$ and $107 \mathrm{TW}$ in the FSC (Berx et al. 2013), the mean volume and heat transports from NorESM1$\mathrm{M}$ of $1.4 \mathrm{~Sv}$ and $56 \mathrm{TW}$ are too low. This is improved by NorESM1-H with a mean volume and heat transport of 2.7 Sv and 124 TW. Through the IFR section NorESM1-M simulates 4.4 Sv and $156 \mathrm{TW}$ and NorESM1-H 4.2 Sv and $179 \mathrm{TW}$, which are both above the observed estimates of 3.8 Sv and $124 \mathrm{TW}$ (Hansen et al. 2015).

In the FB section, current meter moorings have been operated since September 1997 (Ingvaldsen et al. 2004) and allow for calculations of Atlantic water volume and heat transports through the FB (1.8 Sv and $51 \mathrm{TW}$; Skagseth 2008; Skagseth et al. 2011). The current meter moorings 
in the FB does not include the Norwegian Coastal Current, and an associated volume- and heat transport of $1.8 \mathrm{~Sv}$ and 34 TW (Skagseth et al. 2011) must therefore be added to get an estimate of the entire FB section. The resulting Atlantic water volume- and heat transports from observations then add up to $3.6 \mathrm{~Sv}$ and $85 \mathrm{TW}$, which exceed the model estimates of both NorESM1-M (2.4 Sv and $43 \mathrm{TW})$ and NorESM1-H (2.5 Sv and $70 \mathrm{TW})$, and then in particular that of the NorESM1-M. A similar result was found in Ilicak et al. (2016), where NorESM1-M and a range of other CORE2 models were investigated regarding the net heat and volume transports through the entire Barents Sea Opening. The mean net volume transport in NorESM1-M was within their range of observations, but the mean net heat transport was underestimated.

We note that the mean heat transport through the FB increases much more than the volume transport when going from medium to high resolution. This suggest that the Atlantic water temperature in this section is higher in NorESM1-H than in NorESM1-M, which is consistent with Fig. 4 showing a warm bias for NorESM1-H and a cold bias for NorESM1-M.

In summary, we find that mean volume and heat transport into the Nordic Seas and the Barents Sea is improved in FSC and FB for NorESM1-H, i.e., the volume and heat related to the eastern branch of Atlantic water is improved. Concerning the year-to-year variability of the volume transport from the late 1990s to 2008 in IFR and FB, none of the model versions are able to match the observations (not shown). The variability is unchanged between the two model versions.

We have also extracted times series of SST and subsurface salinity from the Irminger Current (IC), the Faroe Current (FC), and the Rockall Trough (RT); the inflowing branches of Atlantic water to the Nordic Seas (Fig. 1). Similar positions were also used in Hátún et al. (2005) to represent hydrographic properties of the inflowing currents. The subsurface salinity is selected at a depth of 200 $\mathrm{m}$ (in the core of Atlantic water). To get a quantitative measure of the similarity between the observed and simulated hydrographic anomalies in the inflowing branches, correlations have been calculated and are listed in Tables 1 and 2 (first and second column) for NorESM1-M and NorESM1-H, respectively. The maximum correlation is found between observed and modeled IC temperature for NorESM1-M (0.70). Regarding IC salinity, there is also a relatively high correlation for NorESM1-M (0.62). According to the results in Tables 1 and 2, NorESM1-M has the largest similarity with observations in the westernmost inflowing branch (IC), whereas NorESM1-H does a slightly better job in the other two branches (FC and RT, with maximum correlation of 0.63 ). This might reflect the fact that NorESM1-H better reproduces the amount of volume and heat going into the Nordic Seas in the FSC. Alternatively, it could be related to the tighter link between hydrographic anomalies in the subpolar region and the Nordic Seas in NorESM1-H than in NorESM1-M, as described in Sect. 3.2.
Table 1 NorESM1-M simulated hydrography ( $\mathrm{T}$ and $\mathrm{S}$ in leftmost column) in the inflowing branches (IC, FC, and RT, see Fig. 1) is correlated with observed hydrography ( $\mathrm{T}_{\mathrm{obs}}$ and $\mathrm{S}_{\mathrm{obs}}$ in uppermost row). Simulated hydrography is also correlated with simulated Subpolar Gyre indices $\left(\mathrm{SPG}_{B T S F}\right.$ and $\left.\mathrm{SPG}_{S S H}\right)$, and simulated hydrography in the center of the Subpolar Gyre $\left(\mathrm{T}_{S P G}\right.$ and $\left.\mathrm{S}_{S P G}\right)$. The maximum correlation is shown and the corresponding time lag is indicated after.
A positive time lag means that the simulated $\mathrm{T}$ or $\mathrm{S}$ in the inflowing branches is lagging. Correlations are calculated with band-pass filtered time series and significant correlations are shown in bold. Some of the correlations at negative time lags are noted with a star, meaning that there is an additional peak correlation at positive time lag but with lower correlation

NorESM1-M

\begin{tabular}{|c|c|c|c|c|c|c|}
\hline & $T_{\text {obs }}$ & $S_{\text {obs }}$ & $S P G_{\text {BTSF }}$ & $\mathrm{SPG}_{\mathrm{SSH}}$ & $\mathrm{T}_{\mathrm{SPG}}$ & $S_{S P G}$ \\
\hline \multicolumn{7}{|l|}{ IC } \\
\hline T & $0.70 / 0$ & & $0.35 /-1$ & $-0.43 / 4$ & $0.39 / 0$ & \\
\hline$S$ & & $0.62 /-1$ & $0.48 / 2$ & $0.49 / 1$ & & $0.73 / 0$ \\
\hline \multicolumn{7}{|c|}{$\mathrm{FC}$} \\
\hline $\mathbf{T}$ & $0.60 / 0$ & & $-0.34 /-3$ & $-0.28 /-3$ & $-0.46 /-3^{*}$ & \\
\hline $\mathbf{s}$ & & $0.47 / 1$ & $-0.45 /-2^{*}$ & $0.53 / 1$ & & $0.60 / 0$ \\
\hline \multicolumn{7}{|c|}{ RT } \\
\hline $\mathbf{T}$ & $0.39 / 0$ & & $0.28 / 3$ & $0.18 / 5$ & $-0.35 /-4^{*}$ & \\
\hline $\mathbf{S}$ & & $0.51 / 0$ & $0.48 / 3$ & $0.56 / 2$ & & $0.67 / 1$ \\
\hline
\end{tabular}


Table 2 Same as Table 1, but for NorESM1-H

\section{NorESM1-H}

\begin{tabular}{|l|l|l|l|l|l|l|}
\hline & $\mathrm{T}_{\text {obs }}$ & $\mathrm{S}_{\text {obs }}$ & $\mathrm{SPG}_{\mathrm{BTSF}}$ & $\mathrm{SPG}_{\text {SSH }}$ & $\mathrm{T}_{\text {SPG }}$ & $\mathrm{S}_{\text {SPG }}$ \\
\hline IC & & & & & & \\
\hline $\mathrm{T}$ & $\mathbf{0 . 3 4 / 0}$ & & $0.34 /-4$ & $\mathbf{0 . 4 6 / 0}$ & $\mathbf{0 . 4 9 / 0}$ & \\
\hline $\mathrm{S}$ & & $\mathbf{0 . 4 4 / - 2}$ & $\mathbf{0 . 4 5 / - 1}$ & $\mathbf{0 . 5 5 / 0}$ & & $-0.52 / 0$ \\
\hline FC & & & & & & \\
\hline $\mathrm{T}$ & $\mathbf{0 . 6 3 / 0}$ & & $-0.25 /-3$ & $-\mathbf{0 . 4 2 / - 3}$ & $\mathbf{0 . 3 1 / 0}$ & \\
\hline $\mathrm{S}$ & & $0.38 / 1$ & $0.37 / 0$ & $0.37 / 0$ & & $-0.33 / 1$ \\
\hline RT & & & & & & \\
\hline $\mathrm{T}$ & $\mathbf{0 . 4 6 / 0}$ & & $\mathbf{0 . 4 7 / 1}$ & $\mathbf{0 . 4 5 / 2}$ & $\mathbf{0 . 4 5 / 3}$ & \\
\hline $\mathrm{S}$ & & $\mathbf{0 . 5 5 / - 1}$ & $\mathbf{0 . 4 5 / 1}$ & $\mathbf{0 . 5 9 / 0}$ & & $-0.35 / 0$ \\
\hline
\end{tabular}

\subsection{Subpolar gyre dynamics differ in high and medium resolution}

In order to better understand the conditions under warm and cold anomalies in the subpolar region, we have calculated correlations between the barotropic streamfunction (depth and zonally integrated volume transport) in each grid point and the CPC time series from St1.

The mean simulated barotropic streamfunction illustrates two main gyres (Fig. 14, bottom panel), the Subpolar Gyre (SPG) and the northernmost part of the Subtropical gyre (STG). The North Atlantic Current flows northeastward at

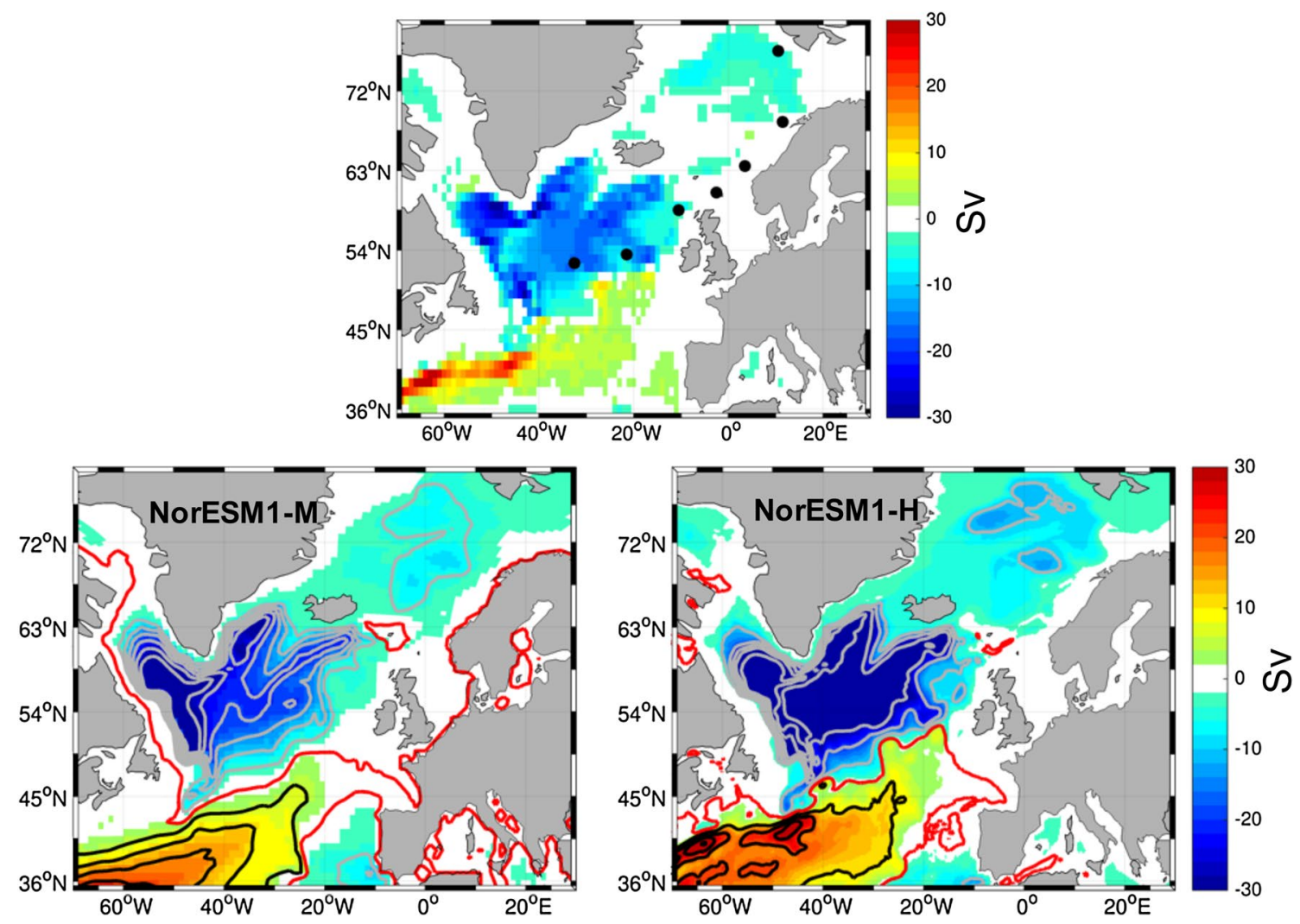

Fig. 14 The difference in the mean barotropic streamfunction for the period 1948-2007 between NorESM1-H and NorESM1-M (top panel), and their respective means (bottom panel). Contours are drawn for the interval [- 30:5:30] for NorESM1-M, and [- 50:10:50] for NorESM1-H. The red line shows where the mean barotropic streamfunction is zero 
the border between the two gyres. In order to better visualize the differences between the two model versions, the simulated fields from both versions have been interpolated to a regular grid $\left(1^{\circ}\right.$ longitude $\times 1^{\circ}$ latitude grid) and then the difference in the barotropic streamfunction is shown in Fig. 14. Overall, the structure of the barotropic streamfunction is similar in the two model versions, but the circulation in NorESM1-H is stronger than in NorESM1-M. Particularly the boundary currents are stronger in NorESM1-H, such as the Gulf Stream and the rim currents in the Iceland and Irminger basins, as well as in the Labrador Sea. This is consistent with the mixed layer ocean currents in Fig. 7.

In both NorESM1-M and NorESM1-H the eastward extension of the Gulf Stream at the northern rim of STG weakens significantly when there is an increase in the temperature at St1 (Fig. 15). In the SPG the sign of the correlations is similar in both model versions, but regions with significant correlations differ. In NorESM1-M the Labrador Current weakens significantly when there is a warm anomaly at St1, which suggests that less cold and fresh Arctic Water is brought southwards during warm anomalies at St1.

In NorESM1-H we see that central parts of the SPG strengthen significantly, but most dominant is the change at the northern rim of the gyre; the branch of Atlantic water turning westward south of Iceland weakens significantly. Hence, increased temperatures at St 1 are associated with less water moving eastward in the northern STG and less water moving westward in the northern SPG, which suggest that more Atlantic water is moving with the North Atlantic Current and further into the Nordic Seas. These changes in the ocean circulation likely bring a warm anomaly into the subpolar region.

It thus appears that the anomalies at St1 are formed in somewhat different ways in the two model versions. In both versions there is less water moving eastward in the STG, but the changes in the SPG differs. The change at the northern rim of the SPG in the high resolution could be a result of the strong boundary currents, which are not resolved in the medium resolution (Fig. 7). The influence of Atlantic water in the SPG is illustrated in Fig. 6, showing that warm Atlantic water reaches much further west in NorESM1-H than in NorESM1-M.

The strength of the SPG circulation, i.e., SPG indices, are calculated in two different ways: Firstly, in terms of the barotropic streamfunction, using the minimum in the subpolar region each year, and secondly, by the first EOF mode of detrended sea surface height (SSH). The area used for the EOF analysis covers most of the North Atlantic from $26^{\circ} \mathrm{N}$ to the Greenland-Scotland Ridge (Fig. 1) and is similar to what was used in Hátún et al. (2005).

Based on observed SSH and hydrography, Hátún et al. (2005) found a relationship between the SPG EOF index and the hydrography of the inflowing branches to the Nordic Seas. More cold and fresh water from the SPG was transported into the Nordic Seas when the SPG was strong, and more warm and saline water from the STG was transported northwards when the SPG was weak. The shape of the gyre might explain such a relationship: a strong gyre extends further east, and thereby brings more cold and fresh water into the northeastern North Atlantic, whereas a weak gyre contracts and gives a gateway for warm and saline water to the north (Hátún et al. 2005). However, a more recent study finds that the variability in the strength and the extent of the SPG is explained by the second EOF of detrended $\mathrm{SSH}$, and that this is not influencing the property variability of STG waters in the eastern subpolar region (Foukal and Lozier 2017). They find that the first EOF is co-varying with the $\mathrm{NAO}$, and that this is not dominating the variability of
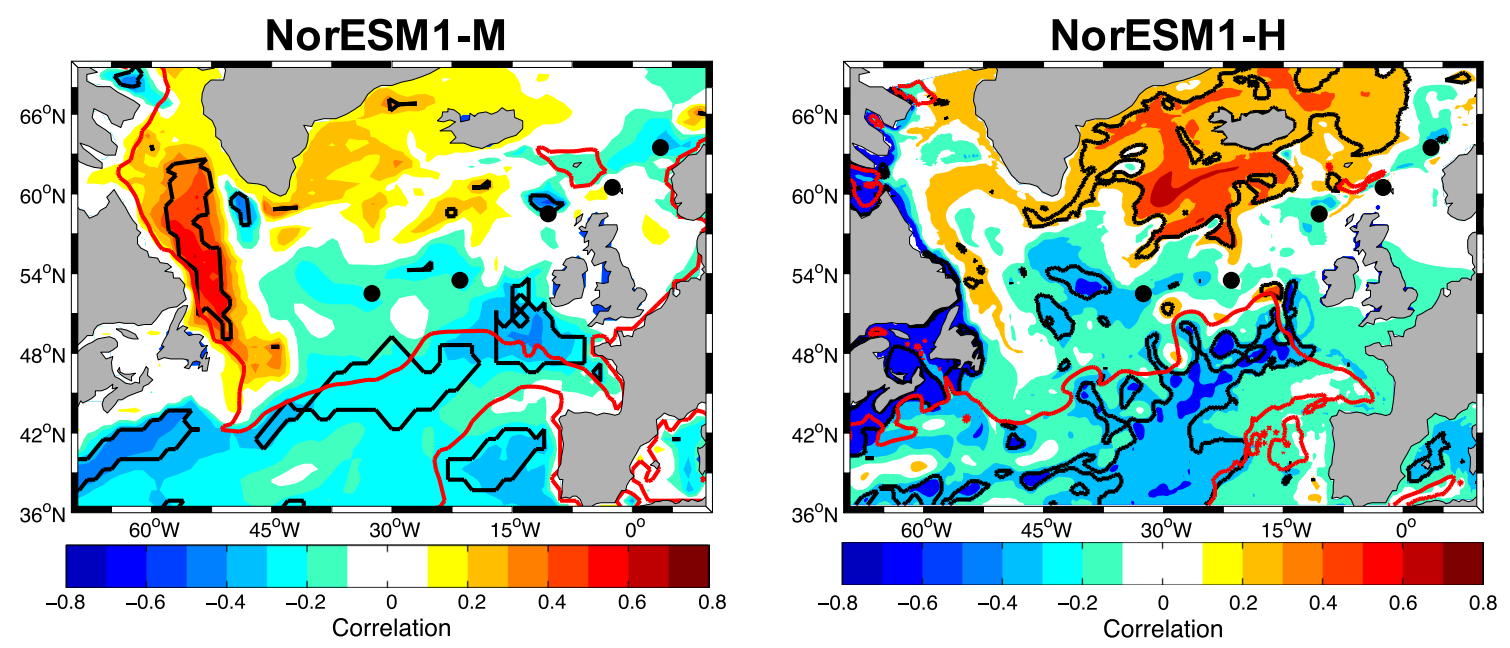

Fig. 15 Correlation between the time series at St1 in the CPC analysis (Fig. 11) and band-pass filtered barotropic stream function in each grid point. The red line shows where the mean barotropic streamfunction is zero, and the correlations within the black line are significant 
the strength and extent of the SPG. Hence, by here applying the first EOF of detrended SSH we are assessing the link between the North Atlantic Ocean circulation, manifested as the dominant mode of $\mathrm{SSH}$, and the hydrography of inflowing water to the Nordic Seas. We are not, however, investigating the relationship between this first EOF and the extent of the SPG. As we are using the same definitions as in Hátún et al. (2005), we will refer to the first EOF as the SPG EOF index.

Tables 1 and 2 (third and fourth column) show the maximum correlation within a time lag of 5 years, as, according to the literature (Hátún et al. 2005), anomalies in the subpolar region reach the entrance of the Nordic Seas within 5 years. We find significant and positive correlations between the SPG EOF index and the salinity of all inflowing branches in NorESM1-M. However, for temperature the situation is more complex, with the correlations being either non-significant or negative. The relationship between the SPG EOF index and the inflowing branches in NorESM1-M are thus consistent with Hátún et al. (2005) when it comes to salinity, but not when considering temperature. Similar results are found when using the SPG index based on the barotropic streamfunction, but with slightly lower correlations.

In NorESM1-H, we find significant and positive relationships between the SPG EOF index and both salinity and temperature for IC and RT, but not for FC (either non-significant or negative). Similar relationships are found for the streamfunction SPG index, except for the temperature in the IC. Thus, regarding IC and RT, the results are consistent with Hátún et al. (2005). The reason for NorESM1-H to not have a link between FC and SPG (as for IC and RT), could simply be because FC is located north of the GreenlandScotland Ridge, whereas IC and RT are located south of the Greenland-Scotland Ridge. This could imply that it is difficult for the model to pass on hydrographic anomalies from the subpolar region to the Nordic Seas. Although SST and sub-surface anomalies appears to propagate northwards across the easternmost part of the Greenland-Scotland Ridge in NorESM1-H (Figs. 11, 12), the volume transport variability across IFR (just south of FC; Fig. 1) is not reproduced in the model.

We did also find some significant correlations outside the time frame of 5 years. One possible reason for these multiple peak correlations is that the signal in the temperature or salinity is repetitive. Indeed, this is what we see in Figs. 11 and 12 (CPC analysis of temperature and salinity). Another possible explanation is that anomalies, entering the Nordic Seas in the east, are travelling around the rim of the Nordic Seas and exiting in the west close to the IC (e.g., Escudier et al. 2013).

We have furthermore assessed in both model versions how the hydrography in the center of the SPG relates to the hydrography in the inflowing branches to the Nordic
Seas (fifth and sixth column in Tables 1,2). This is a test to what extent the hydrography of the inflowing branches is influenced by the variability of the cold and fresh water within the SPG. Comparing the results in Tables 1 and 2, the first we note is that salinity of the inflowing branches and the SPG center is highly related in NorESM1-M. Also, the SPG index and the salinity of the branches are linked in NorESM1-M, as described earlier. In NorESM1-H the opposite is the case, where temperature is what connects the inflowing branches and the center of the SPG. The time lag (3 years) between the center of the SPG and RT is also consistent with Fig. 9, having a time lag from St1 to St3 of a couple of years. Otherwise, the time lags are rather short, suggesting that the hydrographic anomalies in the center of the SPG have a rather large spread, which is consistent with the analysis shown in Fig. 13.

\section{Discussion}

Variability on decadal time scales of temperature and salinity associated with the warm Atlantic water pathway is of great scientific interest, as anomalies of such properties can have profound impact on the ocean climate along the pathway, and potentially on northwestern European climate (e.g., Collins and Sinha 2003; Årthun et al. 2017). In this study, our main purpose is to investigate to what extent a forced global ocean-sea ice model is able to represent known characteristics of the Atlantic water pathway. The model used herein, the Norwegian Earth System Model, simulates fairly well the SST anomalies along the Atlantic water pathway. The two model versions have in common a dominant pattern of SST anomalies occurring regularly along the Atlantic water pathway (i.e., 5-10 years between each warm anomaly), where the anomalies are largely in phase with observations. This might suggest that the SST variability is to some extent controlled by the common atmospheric forcing (COREv2) in the two experiments. This is in agreement with Danabasoglu et al. (2016), showing that a range of models forced with COREv2 (including NorESM1-M used herein) capture well the observed variability of North Atlantic SSTs. A realistic atmospheric forcing might produce realistic ocean surface currents (such as location and speed), and thereby a more realistic ocean surface circulation that can carry the SST anomalies poleward. However, the travel time from the subpolar region to the Fram Strait is more realistic in the high resolution than in the medium resolution, demonstrating the advantages with a higher resolution model.

The difference in the travel time for the two model versions might lay, as indicated above, in their ability to simulate a realistic ocean circulation. This is probably due to increased resolution and more realistic topography in the high resolution, which again improve the circulation and 
volume transports (Sandø et al. 2014). Accordingly, the average volume and heat transport brought from the subpolar region to the Nordic Seas with the easternmost branch is better reproduced in the high resolution than in the medium resolution. In general, the high resolution has stronger and narrower boundary currents than the medium resolution (Fig. 7), and, consistently, we found that Atlantic water in the high resolution extends further west along the northern boundary of the SPG than in the medium resolution. This is in line with another study comparing a non-eddy resolving and an eddy-resolving climate model, which found that increased mean northward ocean heat transport in the Nordic Seas in the eddy-resolving model is not due to eddies, but due to changes in the mean circulation (Kirtman et al. 2012).

Temporal variability of the modeled volume transports of Atlantic water at the entrance of the Nordic Seas is, on the other hand, not realistic in any of the model versions. The same inconsistency for the IFR inflow was found in a regional version of MICOM; the same ocean model as used herein, with $13 \mathrm{~km}$ resolution (Sandø et al. 2012), which suggests that improving the resolution to a range of $\mathrm{O}(\sim 10 \mathrm{~km})$ does not help to improve the variability of the IFR inflow. Likewise, in this study the variability of the Atlantic inflow to the Nordic Seas in the medium resolution is not improved with higher resolution.

Similarly, the simulated subsurface salinity anomalies along the Atlantic water pathway are not in phase with observations in any of the model versions, in contrast to the SST anomalies. This could be a result of the model's failure in reproducing the variability of volume transports of Atlantic water into the Nordic Seas. According to Orvik and Skagseth (2005) and Mauritzen at al. (2006), variability of northward transport of salt and heat in the North Atlantic and Nordic Seas is almost entirely controlled by the volume transport on interannual time scales. Since the volume transport is not correct in the two model versions, they can neither reproduce the transport of salt or heat, and hence, the subsurface salinity anomalies do not appear to occur at the correct time. The SST anomalies are, on the other hand, more directly influenced by the (common COREv2) atmospheric forcing at surface and are therefore more or less mutually similar to the observations. This also indicates that the atmospheric forcing has a limited influence on the subsurface circulation.

The origin of thermohaline anomalies in the northeastern North Atlantic has previously been related to changes in the gyre circulation (e.g., Hátún et al. 2005). In this study we also find that the high resolution has significant relations between the EOF SPG index, which is the dominant mode of detrended SSH, and the thermohaline properties in two of the inflowing branches (IC and RT). For instance, increasing temperature and salinity of IC and RT is associated with the sea level rising (sinking) in the northern SPG
(STG). Furthermore, analyzing the relation between temperature anomalies in the subpolar region and the barotropic streamfunction in the high resolution, we find that warm anomalies in the subpolar region are related to a significant weakening of the eastward extension of the Gulf Stream within the STG. Further north, there is also a significant weakening along the northern rim of the SPG in the high resolution version. These changes in the gyres associated with a warm anomaly in the subpolar region appear to be consistent with the findings of Häkkinen et al. (2011). They suggested that when the SPG and STG relax due to wind forcing, dynamical changes give a gateway for warm and saline subtropical water to propagate northwards. However, a complete analysis of the origin of the thermohaline anomalies in the northeastern North Atlantic is beyond the scope of this study. We refer the reader to a recent study (and references therein), performing a detailed study of decadal fluctuations in temperature and salinity in the subpolar gyre (Nigam et al. 2018). They suggest a chain of processes, starting with changes in low-frequency NAO and including a detachment of the Gulf Stream excursions that propagates northeastward.

As discussed above, it appears that the common atmospheric forcing causes the good synchronization between simulated and observed SST anomalies. It would therefore be of particular interest to investigate whether or not the properties of such temperature anomalies (e.g., regular occurrence, travel time) would be reproduced in a coupled climate model. These coupled models are used for decadal climate prediction, serving dynamical prediction systems. We therefore recommend using a similar analysis as that performed here on coupled climate models and their respective climate predictions. In this way, we can test to what extent the mechanism investigated herein is represented in dynamical prediction systems. A recent study show that dynamical prediction systems have problems in conveying predictive skill from the subpolar region to the Nordic Seas (Langehaug et al. 2017), and one potential candidate causing the failure in prediction could be the model's inability to reproduce the correct path, travel time, and occurrence of thermohaline anomalies.

High-resolution coupled climate model and their performance have been explored in several studies during the last decade (e.g., Shaffrey et al. 2009; Bryan et al. 2010; Delworth et al. 2012; Kirtman et al. 2012; Marzocchi et al. 2015; Siqueira and Kirtman 2016). In general, these models improve on many of the shortcomings in coarser resolution, non-eddy resolving climate models, as described in a recent review (Hewitt et al. 2017 and references therein). In particular, air-sea interaction in the Gulf Stream is improved in eddy-resolving coupled climate models, and hence, would be necessary to resolve also in dynamical prediction systems (Siqueira and Kirtman 2016). In the region targeted 
in this study, the eddies role in the mean northward ocean heat transport have shown to be negligible (e.g., Volkov et al. 2008; Kirtman et al. 2012). Therefore, the benefits of increased horizontal ocean resolution in this region is rather a better representation of the mean circulation and transports. This we find to be essential for simulating a more realistic travel time for ocean anomalies.

\section{Summary and conclusions}

The poleward propagation of thermohaline anomalies is considered to be a main source of climate predictability (Årthun and Eldevik 2016; Årthun et al. 2017; Yeager and Robson 2017). The purpose of this study is twofold: (1) We investigate how properties associated with the warm Atlantic water is expressed along its pathway, using observational data and a forced global ocean-sea ice model. We selected seven stations from the subpolar region to the Fram Strait, in order to capture a possible progression of thermohaline anomalies along the pathway. (2) We test the sensitivity of the results to the horizontal resolution of the ocean model, where one experiment has $1^{\circ}$ resolution (medium resolution) and the other has $0.25^{\circ}$ resolution (high resolution).

We found that both model versions herein are capable of reproducing some characteristics of the warm Atlantic water pathway, such as the occurrence of warm (or cold) anomalies every 5-10 years along the pathway, in agreement with observations. However, the higher resolution is outperforming the medium resolution with respect to travel time along the Atlantic water pathway and heat transport into the Nordic Seas. This, we argue, is due to a more realistic ocean circulation in the higher resolution version, consistent with other studies comparing different ocean resolutions.

In this study we have used a forced global ocean-sea ice model, whereas a coupled climate model forms the core of a dynamical prediction system. It is unknown how skills in the forced version is transferred to the coupled version, and we therefore recommend that the analysis presented herein is tested on different models, and in particular, on coupled climate models and their respective climate predictions. Hopefully, this will reduce systematic model errors and improve representation of key properties and mechanisms related to the Atlantic water pathway, and thereby, lead to more reliable climate predictions in the subpolar North Atlantic and Nordic Seas, as well as over the neighboring continents.

Acknowledgements The research leading to these results have received funding from the European Union 7th Framework Programme (FP7 2007-2013) under Grant agreement no. 308299 (HRL). HRL and ABS acknowledge support from the Research Council of Norway (NFR) EPOCASA Project (Grant 229774), and also the NFR NORTH Project (Grant 229763) has provided funding for the study (HRL, ABS, and
MI). MI is also supported by the SKD BASIC Project and Ice2Ice Project that has received funding from FP7 2007-2013 under Grant agreement no. 610055. MA has been funded by the NFR PATHWAY Project (Grant 263223), and the Blue-Action Project (European Union's Horizon 2020 research and innovation program, Grant 727852).

Open Access This article is distributed under the terms of the Creative Commons Attribution 4.0 International License (http://creativeco mmons.org/licenses/by/4.0/), which permits unrestricted use, distribution, and reproduction in any medium, provided you give appropriate credit to the original author(s) and the source, provide a link to the Creative Commons license, and indicate if changes were made.

\section{References}

Årthun M, Eldevik T (2016) On anomalous ocean heat transport toward the Arctic and associated climate predictability. J Clim 29:689704. https://doi.org/10.1175/JCLI-D-15-0448.1

Årthun M, Eldevik T, Smedsrud LH, Skagseth $\varnothing$, Ingvaldsen RB (2012) Quantifying the influence of Atlantic heat on Barents Sea ice variability and retreat. J Clim 25:4736-4743. https://doi. org/10.1175/JCLI-D-11-00466.1

Årthun M, Eldevik T, Viste E, Drange H, Furevik T, Johnson HL, Keenlyside NS (2017) Skillful prediction of northern climate provided by the ocean. Nat Commun. https://doi.org/10.1038/ ncomms 15875

Belkin IM, Levitus S, Antonov J, Malmberg S (1998) "Great Salinity Anomalies" in the North Atlantic. Prog Oceanogr 41:1-68. https ://doi.org/10.1016/S0079-6611(98)00015-9

Bentsen M, Bethke I, Debernard JB, Iversen T, Kirkevåg A, Seland Ø, Drange $\mathrm{H}$, Roelandt C, Seierstad IA, Hoose C, Kristjánsson JE (2013) The Norwegian Earth System Model, NorESM1-M-Part 1: description and basic evaluation of the physical climate. Geosci Model Dev 6:687-720. https://doi.org/10.5194/gmd-6-687-2013

Berx B, Hansen B, Østerhus S, Larsen KM, Sherwin T, Jochumsen $\mathrm{K}$ (2013) Combining in situ measurements and altimetry to estimate volume, heat and salt transport variability through the FaroeShetland Channel. Ocean Sci 9:639-654. https://doi.org/10.5194/ os-9-639-2013

Brambilla E, Talley LD (2008) Subpolar Mode Water in the northeastern Atlantic: 1. Averaged properties and mean circulation. J Geophys Res Oceans. https://doi.org/10.1029/2006JC004062

Bryan FO, Tomas R, Dennis JM, Chelton DB, Loeb NG, McClean JL (2010) Frontal scale air-sea interaction in high-resolution coupled climate models. J Clim 23:6277-6291. https://doi. org/10.1175/2010JCLI3665.1

Carton JA, Chepurin GA, Reagan J, Häkkinen S (2011) Interannual to decadal variability of Atlantic water in the Nordic and adjacent seas. J Geophys Res Oceans. https://doi.org/10.1029/2011J C007102

Chafik L, Nilsson J, Skagseth Ø, Lundberg P (2015) On the flow of Atlantic water and temperature anomalies in the Nordic Seas toward the Arctic Ocean. J Geophys Res Oceans 120:7897-7918. https://doi.org/10.1002/2015JC011012

Chelton DB (1983) Effects of sampling errors in statistical estimation. Deep Sea Research Part A. Oceanogr Res Pap 30:1083-1103. https://doi.org/10.1016/0198-0149(83)90062-6

Chepurin GA, Carton JA (2012) Subarctic and Arctic sea surface temperature and its relation to ocean heat content 1982-2010. J Geophys Res Oceans. https://doi.org/10.1029/2011JC007770 
Collins M, Sinha B (2003) Predictability of decadal variations in the thermohaline circulation and climate. Geophys Res Lett. https:// doi.org/10.1029/2002GL016504

Danabasoglu G, Yeager SG, Bailey D et al (2014) North Atlantic simulations in coordinated ocean-ice reference experiments phase II (CORE-II). Part I: mean states. Ocean Model 73:76-107. https:// doi.org/10.1016/j.ocemod.2013.10.005

Danabasoglu G, Yeager SG, Kim WM et al (2016) North Atlantic simulations in coordinated ocean-ice reference experiments phase II (CORE-II). Part II: inter-annual to decadal variability. Ocean Model 97:65-90. https://doi.org/10.1016/j.ocemo d.2015.11.007

Delworth TL, Rosati A, Anderson W, Adcroft AJ, Balaji V, Benson R, Dixon K, Griffies SM, Lee H, Pacanowski RC, Vecchi GA, Wittenberg AT, Zeng F, Zhang R (2012) Simulated climate and climate change in the GFDL CM2.5 high-resolution coupled climate model. J Clim 25:2755-2781. https://doi.org/10.1175/JCLID-11-00316.1

Escudier R, Mignot J, Swingedouw D (2013) A 20-year coupled oceansea ice-atmosphere variability mode in the North Atlantic in an AOGCM. Clim Dyn 40:619-636. https://doi.org/10.1007/s0038 2-012-1402-4

Fisher RA (1921) On the probable error of a coefficient of correlation deduced from a small sample. Metron 1:3-32

Foukal NP, Lozier MS (2017) Assessing variability in the size and strength of the North Atlantic subpolar gyre. J Geophys Res Oceans. https://doi.org/10.1002/2017JC012798

Fox-Kemper B, Ferrari R, Hallberg R (2008) Parameterization of mixed layer eddies. Part I: theory and diagnosis. J Phys Oceanogr 38:1145-1165. https://doi.org/10.1175/2007JPO3792.1

Furevik T (2001) Annual and interannual variability of Atlantic water temperatures in the Norwegian and Barents Seas: 1980-1996. Deep Sea Research Part I.. Oceanogr Res Pap 48:383-404. https ://doi.org/10.1016/S0967-0637(00)00050-9

Gent PR, Mcwilliams JC (1990) Isopycnal mixing in ocean circulation models. J Phys Oceanogr 20:150-155. https://doi. org/10.1175/1520-0485(1990)020<0150:IMIOCM > 2.0.CO;2

Ghil M, Allen MR, Dettinger MD, Ide K, Kondrashov D, Mann ME, Robertson AW, Saunders A, Tian Y, Varadi F, Yiou P (2002) Advanced spectral methods for climatic time series. Rev Geophys 40:3-1-3-41. https://doi.org/10.1029/2000RG000092

Gregg MC, Sanford TB, Winkel DP (2003) Reduced mixing from the breaking of internal waves in equatorial waters. Nature 422:513-515

Grist JP, Josey SA, Marsh R, Good SA, Coward AC, de Cuevas BA, Alderson SG, New AL, Madec G (2010) The roles of surface heat flux and ocean heat transport convergence in determining Atlantic Ocean temperature variability. Ocean Dyn 60:771-790. https:// doi.org/10.1007/s10236-010-0292-4

Guo C, Ilicak M, Bentsen M, Fer I (2016) Characteristics of the Nordic Seas overflows in a set of Norwegian Earth System Model experiments. Ocean Model 104:112-128. https://doi.org/10.1016/j. ocemod.2016.06.004

Häkkinen S, Rhines PB, Worthen DL (2011) Warm and saline events embedded in the meridional circulation of the northern North Atlantic. J Geophys Res Oceans. https://doi.org/10.1029/2010J C006275

Hallberg R (2013) Using a resolution function to regulate parameterizations of oceanic mesoscale eddy effects. Ocean Model 72:92-103. https://doi.org/10.1016/j.ocemod.2013.08.007

Hansen B, Larsen KMH, Hátún H, Kristiansen R, Mortensen E, Østerhus S (2015) Transport of volume, heat, and salt towards the Arctic in the Faroe Current 1993-2013. Ocean Sci 11:743-757. https ://doi.org/10.5194/os-11-743-2015
Hátún H, Sandø AB, Drange H, Hansen B, Valdimarsson H (2005) Influence of the Atlantic subpolar gyre on the thermohaline circulation. Science 309:1841-1844

He Y, Drange H, Gao Y, Bentsen M (2016) Simulated Atlantic Meridional Overturning Circulation in the 20th century with an ocean model forced by reanalysis-based atmospheric data sets. Ocean Model 100:31-48. https://doi.org/10.1016/j.ocemod.2015.12.011

Hewitt HT, Bell MJ, Chassignet EP et al (2017) Will high-resolution global ocean models benefit coupled predictions on short-range to climate timescales? Ocean Model 120:120-136. https://doi. org/10.1016/j.ocemod.2017.11.002

Holliday NP, Hughes SL, Bacon S, Beszczynska-Möller A, Hansen B, Lavín A, Loeng H, Mork KA, Østerhus S, Sherwin T, Walczowski W (2008) Reversal of the 1960s to 1990s freshening trend in the northeast North Atlantic and Nordic Seas. Geophys Res Lett. https ://doi.org/10.1029/2007GL032675

Horel JD (1984) Complex principal component analysis: theory and examples. J Clim Appl Meteorol 23:1660-1673. https://doi. org/10.1175/1520-0450(1984)023<1660:CPCATA > 2.0.CO;2

Ilicak M, Drange H, Wang Q et al (2016) An assessment of the Arctic Ocean in a suite of interannual CORE-II simulations. Part III: hydrography and fluxes. Ocean Model 100:141-161. https://doi. org/10.1016/j.ocemod.2016.02.004

Ingvaldsen RB, Asplin L, Loeng H (2004) The seasonal cycle in the Atlantic transport to the Barents Sea during the years 19972001. Cont Shelf Res 24:1015-1032. https://doi.org/10.1016/j. csr.004.02.011

Ishii M, Kimoto M, Sakamoto K, Iwasaki S (2006) Steric sea level changes estimated from historical ocean subsurface temperature and salinity analyses. J Oceanogr 62:155-170. https://doi. org/10.1007/s10872-006-0041-y

Kirtman BP, Bitz C, Bryan F et al (2012) Impact of ocean model resolution on CCSM climate simulations. Clim Dyn 39:1303. https:// doi.org/10.1007/s00382-012-1500-3

Knight JR, Allan RJ, Folland CK, Vellinga M, Mann ME (2005) A signature of persistent natural thermohaline circulation cycles in observed climate. Geophys Res Lett. https://doi. org/10.1029/2005GL024233

Krahmann G, Visbeck M, Reverdin G (2001) Formation and propagation of temperature anomalies along the North Atlantic current. J Phys Oceanogr 31:1287-1303. https://doi.org/10.1175/15200485(2001)031<1287:FAPOTA > 2.0.CO;2

Langehaug HR, Rhines PB, Eldevik T, Mignot J, Lohmann K (2012) Water mass transformation and the North Atlantic Current in three multicentury climate model simulations. J Geophys Res 117:C11001. https://doi.org/10.1029/2012JC008021

Langehaug HR, Matei D, Eldevik T, Lohmann K, Gao Y (2017) On model differences and skill in predicting sea surface temperature in the Nordic and Barents Seas. Clim Dyn 48:913-933. https:// doi.org/10.1007/s00382-016-3118-3

Large WG, Yeager S (2004) Diurnal to decadal global forcing for ocean and sea-ice models: The data sets and flux climatologies. NCAR Technical Note NCAR/TN-460+STR. https://doi.org/10.5065/ D6KK98Q6

Large WG, Yeager SG (2009) The global climatology of an interannually varying air-sea flux data set. Clim Dyn 33:341-364. https:// doi.org/10.1007/s00382-008-0441-3

Large WG, McWilliams JC, Doney SC (1994) Oceanic vertical mixing: a review and a model with a nonlocal boundary layer parameterization. Rev Geophys 32:363-403. https://doi.org/10.1029/94RG0 1872

Latif M, Keenlyside NS (2011) A perspective on decadal climate variability and predictability. Deep Sea Research Part II: topical. Stud Oceanogr 58:1880-1894. https://doi.org/10.1016/j. dsr2.2010.10.066 
Legg S, Hallberg RW, Girton JB (2006) Comparison of entrainment in overflows simulated by z-coordinate, isopycnal and non-hydrostatic models. Ocean Model 11:69-97. https://doi.org/10.1016/j. ocemod.2004.11.006

Marzocchi A, Hirschi JJ, Holliday NP, Cunningham SA, Blaker AT, Coward AC (2015) The North Atlantic subpolar circulation in an eddy-resolving global ocean model. J Mar Syst 142:126-143. https://doi.org/10.1016/j.jmarsys.2014.10.007

Matei D, Pohlmann H, Jungclaus J, Müller W, Haak H, Marotzke J (2012) Two tales of initializing decadal climate prediction experiments with the ECHAM5/MPI-OM model. J Clim 25:8502-8523. https://doi.org/10.1175/JCLI-D-11-00633.1

Mauritzen C, Hjøllo SS, Sandø AB (2006) Passive tracers and active dynamics: a model study of hydrography and circulation in the northern North Atlantic. J Geophys Res Oceans. https://doi. org/10.1029/2005JC003252

Meehl GA, Goddard L, Boer G et al (2014) Decadal climate prediction: an update from the trenches. Bull Am Meteor Soc 95:243-267. https://doi.org/10.1175/BAMS-D-12-00241.1

Menary MB, Hodson DLR, Robson JI, Sutton RT, Wood RA, Hunt JA (2015) Exploring the impact of CMIP5 model biases on the simulation of North Atlantic decadal variability. Geophys Res Lett. https://doi.org/10.1002/2015GL064360

Msadek R, Delworth TL, Rosati A, Anderson W, Vecchi G, Chang Y, Dixon K, Gudgel RG, Stern W, Wittenberg A, Yang X, Zeng F, Zhang R, Zhang S (2014) Predicting a decadal shift in north atlantic climate variability using the GFDL forecast system. J Clim 27:6472-6496. https://doi.org/10.1175/JCLI-D-13-00476.1

Nigam S, Ruiz-Barradas A, Chafik L (2018) Gulf stream excursions and sectional detachments generate the decadal pulses in the atlantic multidecadal oscillation. Climate J. https://doi.org/10.1175/ JCLI-D-17-0010.1

O’Mahony M (1986) Sensory evaluation of food: statistical methods and procedures. Dekker, New York

Oberhuber JM (1993) Simulation of the Atlantic circulation with a coupled sea ice-mixed layer-isopycnal general circulation model. Part I: model description. J Phys Oceanogr 23:808-829. https://doi. org/10.1175/1520-0485(1993)023<0808:SOTACW > 2.0.CO;2

Orvik KA, Niiler P (2002) Major pathways of Atlantic water in the northern North Atlantic and Nordic Seas toward Arctic. Geophys Res Lett 29:2. https://doi.org/10.1029/2002GL015002

Orvik KA, Skagseth $\varnothing(2005)$ Heat flux variations in the eastern Norwegian Atlantic Current toward the Arctic from moored instruments, 1995-2005. Geophys Res Lett. https://doi. org/10.1029/2005GL023487

Pollard RT, Read JF, Holliday NP, Leach H (2004) Water masses and circulation pathways through the Iceland Basin during Vivaldi 1996. J Geophys Res 109:C04004. https://doi.org/10.1029/2003J C002067

Rattan S, Myers PG, Treguier A-M, Theetten S, Biastoch A, Böning C (2010) Towards an understanding of Labrador Sea salinity drift in eddy-permitting simulations. Ocean Model 35:77-88. https:// doi.org/10.1016/j.ocemod.2010.06.007

Rayner NA, Parker DE, Horton EB, Folland CK, Alexander LV, Rowell DP, Kent EC, Kaplan A (2003) Global analyses of sea surface temperature, sea ice, and night marine air temperature since the late nineteenth century. J Geophys Res Atmos. https://doi. org/10.1029/2002JD002670

Robson JI, Sutton RT, Smith DM (2012) Initialized decadal predictions of the rapid warming of the North Atlantic Ocean in the mid 1990s. Geophys Res Lett. https://doi.org/10.1029/2012GL053370

Sand $\varnothing$ AB, Nilsen JEØ, Eldevik T, Bentsen M (2012) Mechanisms for variable North Atlantic-Nordic seas exchanges. J Geophys Res Oceans. https://doi.org/10.1029/2012JC008177

Sandø AB, Melsom A, Budgell WP (2014) Downscaling IPCC control run and future scenario with focus on the Barents Sea. Ocean Dyn 64:927-949. https://doi.org/10.1007/s10236-014-0731-8

Shaffrey LC, Stevens I, Norton WA et al (2009) U.K. HiGEM: the new U.K. high-resolution global environment model-model description and basic evaluation. J Climate 22:1861-1896. https://doi. org/10.1175/2008JCLI2508.1

Simmons HL, Jayne SR, Laurent LCS, Weaver AJ (2004) Tidally driven mixing in a numerical model of the ocean general circulation. Ocean Model 6:245-263. https://doi.org/10.1016/S1463 -5003(03)00011-8

Siqueira L, Kirtman BP (2016) Atlantic near-term climate variability and the role of a resolved Gulf Stream. Geophys Res Lett 43:3964-3972. https://doi.org/10.1002/2016GL068694

Skagseth $\varnothing$ (2008) Recirculation of Atlantic water in the western Barents Sea. Geophys Res Lett. https://doi.org/10.1029/2008GL0337 85

Skagseth Ø, Drinkwater KF, Terrile E (2011) Wind- and buoyancyinduced transport of the Norwegian Coastal Current in the Barents Sea. J Geophys Res Oceans. https://doi.org/10.1029/2011J C006996

Treguier AM, Theetten S, Chassignet EP, Penduff T, Smith R, Talley L, Beismann JO, Böning C (2005) The North Atlantic subpolar gyre in four high-resolution models. J Phys Oceanogr 35:757-774. https://doi.org/10.1175/JPO2720.1

Volkov DL, Lee T, Fu L-L (2008) Eddy-induced meridional heat transport in the ocean. Geophys Res Lett 35:L2060. https://doi. org/10.1029/2008GL035490

Yashayaev I, Seidov D (2015) The role of the Atlantic water in multidecadal ocean variability in the Nordic and Barents Seas. Prog Oceanogr 132:68-127. https://doi.org/10.1016/j.pocea n.2014.11.009

Yeager SG, Robson JI (2017) Recent progress in understanding and predicting Atlantic decadal climate variability. Curr Clim Change Rep 3:112-127. https://doi.org/10.1007/s40641-017-0064-z

Yeager SG, Karspeck AR, Danabasoglu G (2015) Predicted slowdown in the rate of Atlantic sea ice loss. Geophys Res Lett 42:1070410713. https://doi.org/10.1002/2015GL065364 